\title{
ANALYZING THE EFFECT OF MID-RISE DEVELOPMENT ON RETAIL VIBRANCY
} IN THE BEACH

by

Anna Golovkin

BES, University of Waterloo, 2014

\author{
A Major Research Paper \\ presented to Ryerson University \\ in partial fulfilment of the \\ requirements for the degree of \\ Master of Planning \\ in the Program of \\ Urban Development
}

Toronto, Ontario, Canada, 2016

(C) Anna Golovkin 2016 
I hereby declare that I am the sole author of this MRP. This is a true copy of the MRP, including any required final revisions.

I authorize Ryerson University to lend this MRP to other institutions or individuals for the purpose of scholarly research

I further authorize Ryerson University to reproduce this MRP by photocopying or by other means, in total or in part, at the request of other institutions or individuals for the purpose of scholarly research.

I understand that my MRP may be made electronically available to the public. 


\title{
ANALYZING THE EFFECT OF MID-RISE DEVELOPMENT ON RETAIL VIBRANCY IN THE BEACH
}

(C) Anna Golovkin 2016

\author{
Master of Planning \\ in \\ Urban Development \\ Ryerson University
}

\begin{abstract}
In order to meet provincially-mandated growth targets, the City of Toronto has embraced mid-rise infill development along transit-supported avenues as the preferred approach to intensification and reurbanization. In the Beach neighbourhood, growing development pressure along Queen Street East within the Woodbine Beach Precinct has resulted in a departure from fine grain retail, which is still prominent in the eastern part of the neighbourhood. Using a set of key retail vibrancy indicators, this study explores how this new built form is affecting retail businesses on an important historic main street. Implications regarding the existing retail planning approach are discussed, as well as recommendations for strengthening city-wide retail policy, and in turn retail vibrancy in the Beach neighbourhood.
\end{abstract}

Keywords: retail vibrancy, main street, fine grain, mid-rise, retail development, Toronto 


\section{ACKNOWLEDGEMENTS}

First, I would like to thank my supervisor, Dr. Steven Webber. His guidance and feedback kept me on the right track as I navigated the murky waters of Toronto's retail planning landscape. This major research project would have not been possible without the patience and reassurance he showed me throughout this four month process.

I would also like to express my deep appreciation for my dedicated and insightful second reader, David Fitzpatrick (Special Projects at the Chief Planners Office). He played an integral role in the shaping of my research proposal, helping me formulate a coherent vision for this paper. He should also get some kind of "fastest second reader" award because his 7-hour turnaround is no small feat!

Special thanks to all the people that I interviewed. Your time and interest in my work was and continues to be greatly appreciated. I would also like to thank the Centre for the Study of Commercial Activity, specifically Tony Hernandez, who supplied me with comprehensive retail store data for the Beach neighbourhood.

I would like to dedicate this work to my mom and dad, who probably still don't know what my research topic is but are immensely proud of me and my accomplishments.

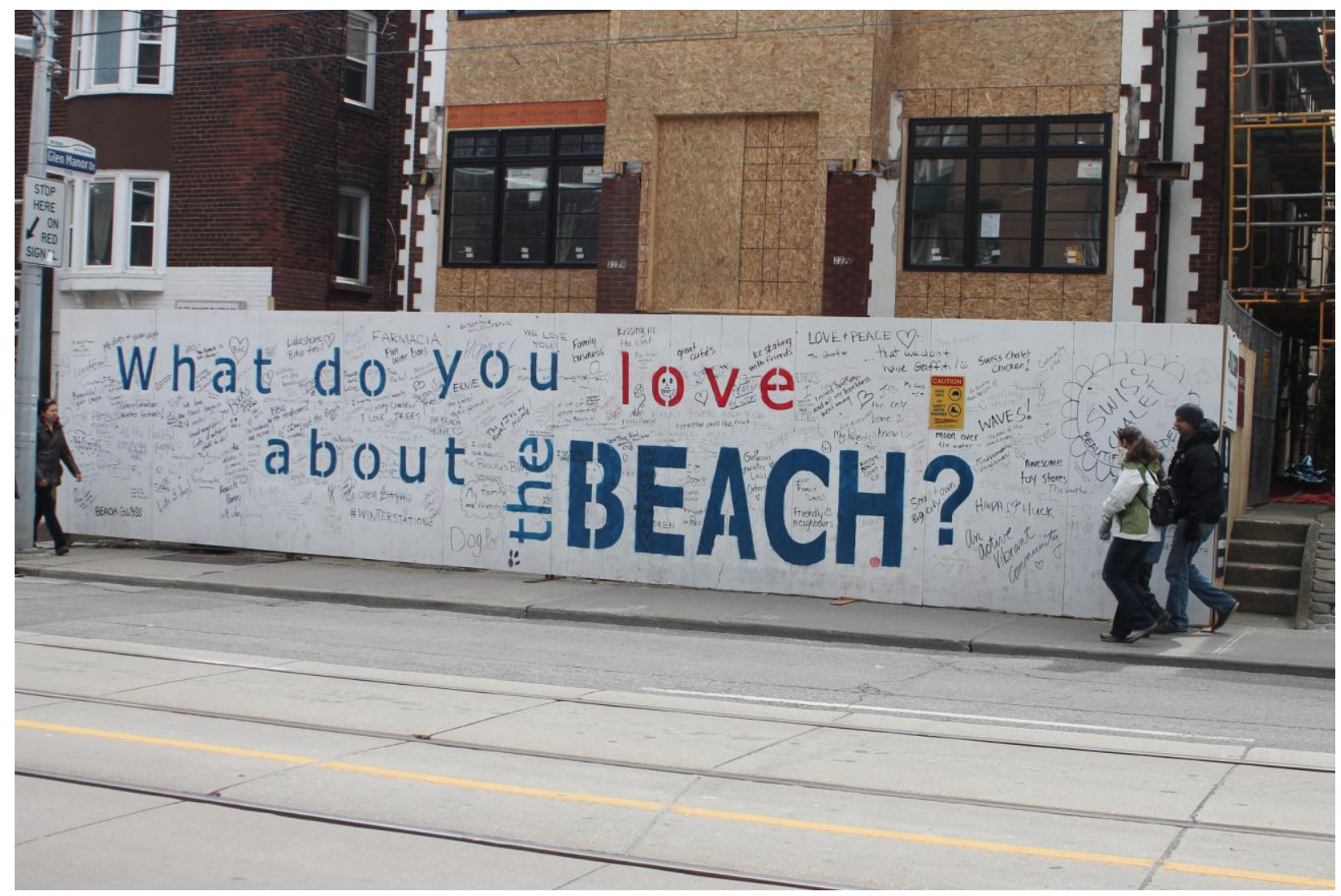




\section{TABLE OF CONTENTS}

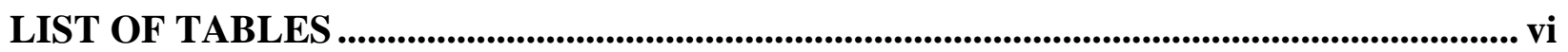

LIST OF FIGURES .................................................................................................... vi

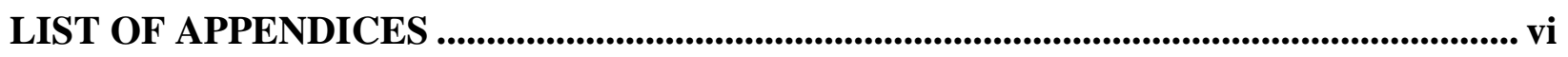

CHAPTER 1: INTRODUCTION.................................................................................................. 1

1. THE BEACH....................................................................................... 2

2. POLICY CONTEXT ............................................................................... 3

3. GREY AND PEER-REVIEWED LITERATURE ......................................... 8

CHAPTER 2: METHOD ...................................................................................................... 13

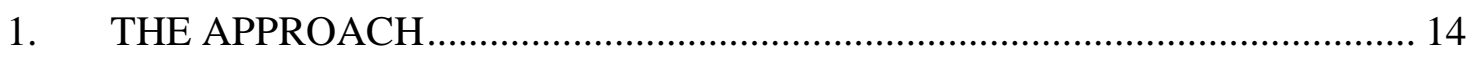

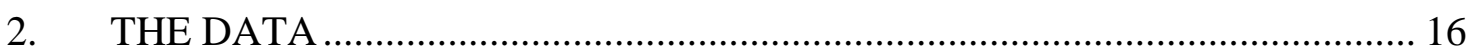

CHAPTER 3: HEALTH INDICATORS OF RETAIL VIBRANCY ....................................... 19

1. RETAIL COMPETITIVENESS ............................................................... 19

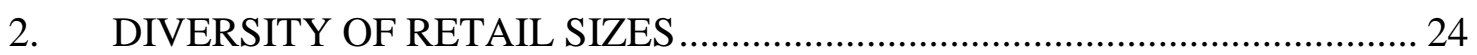

3. PROPORTION OF VACANT PROPERTIES ......................................... 27

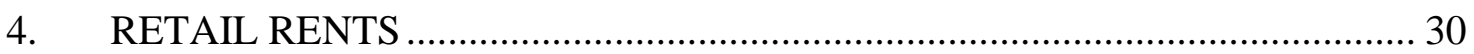

5. RETAIL REPRESENTATION AND NEW POLICY DIRECTIONS .............. 31

6. PUBLIC REALM AND ENVIRONMENTAL QUALITY ............................. 35

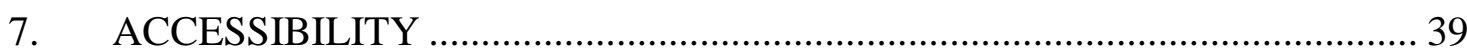

8. CUSTOMER VIEWS \& BEHAVIOUR AND TRAFFIC FLOWS .................. 42

9. SAFETY \& OCCURRENCE OF CRIME ..................................................... 43

10. SOCIOECONOMIC DEMOGRAPHICS ....................................................... 44

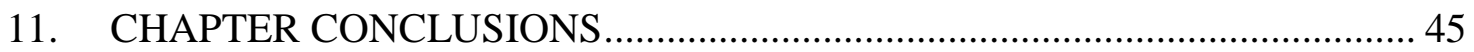

CHAPTER 4: DISCUSSION AND RECOMMENDATIONS.................................................. 46

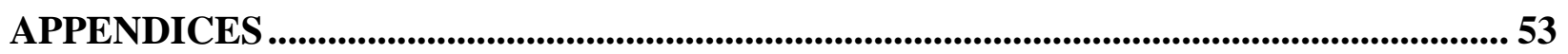

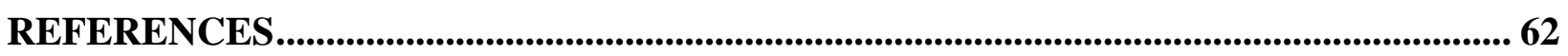

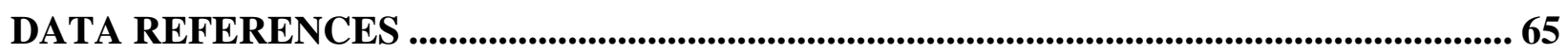




\section{LIST OF TABLES}

Table 1: Health Indicators of Retail Vibrancy

Table 2: Number of Commercial Tenants in Retail Categories which Support Complete Communities, 2015

Table 3: Retail Mix in Woodbine Beach and Kew Beach, 2015

Table 4: Representation of Retail Types, 2015

Table 5: Proportion of Commercial Tenants by Market Size, 2015

Table 6: Walk, Transit and Bike Score by Precinct

Table 7: Number of Crime Occurrences by Neighbourhood, 2011

\section{LIST OF FIGURES}

Figure 1: The Beach and its Three Precincts

Figure 2: Excerpt of Map 21 of Toronto's Official Plan

Figure 3: Map of Study Areas

Figure 4: Spatial Distribution of Retail Mix, 2015

Figure 5: Retail Unit Size based on Square Metres, 2015

Figure 6: Spatial Distribution of Retail Unit Sizes, 2015

Figure 7: Vacancy Rate between 2011 and 2015

Figure 8: Semi-private and Public Facilities near the Study Areas

Figure 9: Accessibility to the Study Areas

\section{LIST OF APPENDICES}

Appendix 1: Additional Information about CSCA data

Appendix 2: Interview Questions for Stakeholders

Appendix 3: Demographic Ring Study (1 and 3 kilometre buffer)

Appendix 4: Additional Photographs of Study Areas 


\section{CHAPTER 1: INTRODUCTION}

While high-rise development has been prevalent in Toronto's downtown core since the late 1960s, mid-rise development has only recently grown popular within the city's inner suburbs. This change came in light of new provincial policy directions regarding the intensification and redevelopment of urban areas more than a decade ago. In the hope of building complete $^{1}$ and more compact $^{2}$ communities, large municipalities implemented policies to direct mid-rise development, which feature a variety of uses ${ }^{3}$, to transit-supported areas. Some of this development has occurred on existing main streets impacting the overall vitality and viability of these historically significant streets.

In North America, the term "main street" is used to describe historic commercial streets within the city core (Carmona 2015). These streets often remain pedestrian-oriented because their establishment pre-dates the predominance of the automobile. Primarily characterised by unplanned fine grain retail, main streets feature one to two storey structures which accommodate independent businesses and small chain stores at grade. As opposed to the car-oriented development of the mid- $20^{\text {th }}$ century, main streets support local residents by maintaining a pedestrian-friendly streetscape and providing a variety of options for shopping, dining and gathering. They are a fundamental component of the neighborhood's identity, facilitating opportunities for social interaction and integration (Griffiths et al 2008).

Over the last century, major shifts in market demand and consumer behaviour have had an indirect impact on the viability of retail main streets. Unlike the threat of regional retail centres and the steady rise of car ownership (Carmona, 2015; Grant, 2002), infill development is a direct pressure on the physical character and social context of main streets. Therefore poorly implemented mid-rise policies may have broader implications on the surrounding neighbourhood, impacting retail characteristics such as average cost per square foot, retail mix and distribution, and size of catchment area.

Queen Street is one of the most iconic main streets in the City of Toronto. Named after Queen Victoria, this east-west street extends more than 14 kilometres across five diverse and distinct neighbourhoods (City of Toronto 2010, A-29). The easternmost neighbourhood along Queen Street is the Beach; a relatively stable community which enjoys a vibrant public realm connected by a busy

\footnotetext{
1 "Complete communities meet people's needs for daily living ... by providing convenient access to an appropriate mix of jobs, local services, a full range of housing, and community infrastructure... [as well as]... Convenient access to public transportation and ... non-motorized travel." (MPIR, 2006, p. 48)

2 "A land-use pattern that encourages efficient use of land, walkable neighbourhoods, mixed land uses, proximity to transit and reduced need for infrastructure. Compact urban form can include ... walk-up apartments, multi-storey commercial developments, and apartments or offices above retail.” (MPIR, 2006, p.48)

${ }^{3}$ Primarily residential and commercial uses.
} 
commercial street, and a network of ravines and parks. However, mid-rise development in the west part of the Beach neighbourhood over the last 15 years has been a significant departure from the fine grain retail still prominent in the eastern part of the neighbourhood.

This study uses a mixed methods approach to analyze the effect of mid-rise development on the vibrancy of an otherwise well-established retail district in the Beach neighbourhood. First, a brief description of the historical and policy context of the neighbourhood sets the stage for the analysis. Next a literature review illustrates the fragmented and interdisciplinary nature of the existing body of knowledge on retail main streets. This is followed by a methods chapter outlining the site selection process and the analytical approach used for assessing the commercial strip. Later, the problem investigation chapter presents and analyzes the findings, which leads to a discussion about implications and recommendations in the final chapter.

\section{THE BEACH}

The City of Toronto began annexing the Beach in 1887. The neighbourhood's reputation as a lake resort town was earned due to its proximity to Lake Ontario (City of Toronto, $2012 \mathrm{~b}$ ). At the turn of the century, the expansion of streetcar development outside Toronto's existing urban boundary resulted in the rise of the "streetcar suburb" (Solomon 2007). Pushed out by industrial development, many commercial and residential uses clustered around transit corridors establishing new commercial areas outside of the core. The Beach not only benefited from streetcar development along Queen Street East and Kingston Road, but also the draining of parts of Ashbridges Bay, a significant natural barrier between the City of Toronto and the Beach (Barc 2010). The Lee and Queen intersection, in the Kew Beach Precinct, was believed to be the commercial centre of the neighbourhood because prominent institutions like Smith's Grocery Store, Dominion Bank, and the Beaches Library were situated there (City of Toronto, 2012 b).

While amusement parks, recreational areas and resorts were built to support summer tourism, most of these tourist destinations were closed by the 1920s to accommodate permanent settlement expanding eastward from the city. After buying up major parcels of land in the neighbourhood, the City began building schools, churches, and parks. Opened in 1932, the Beaches Park along the waterfront became one of the largest public parks in the neighbourhood (Campbell and Myrvold 1988). While the Beach has changed significantly since it was annexed, its historical importance remains imbedded in its distinct physical character and historic landmarks. 


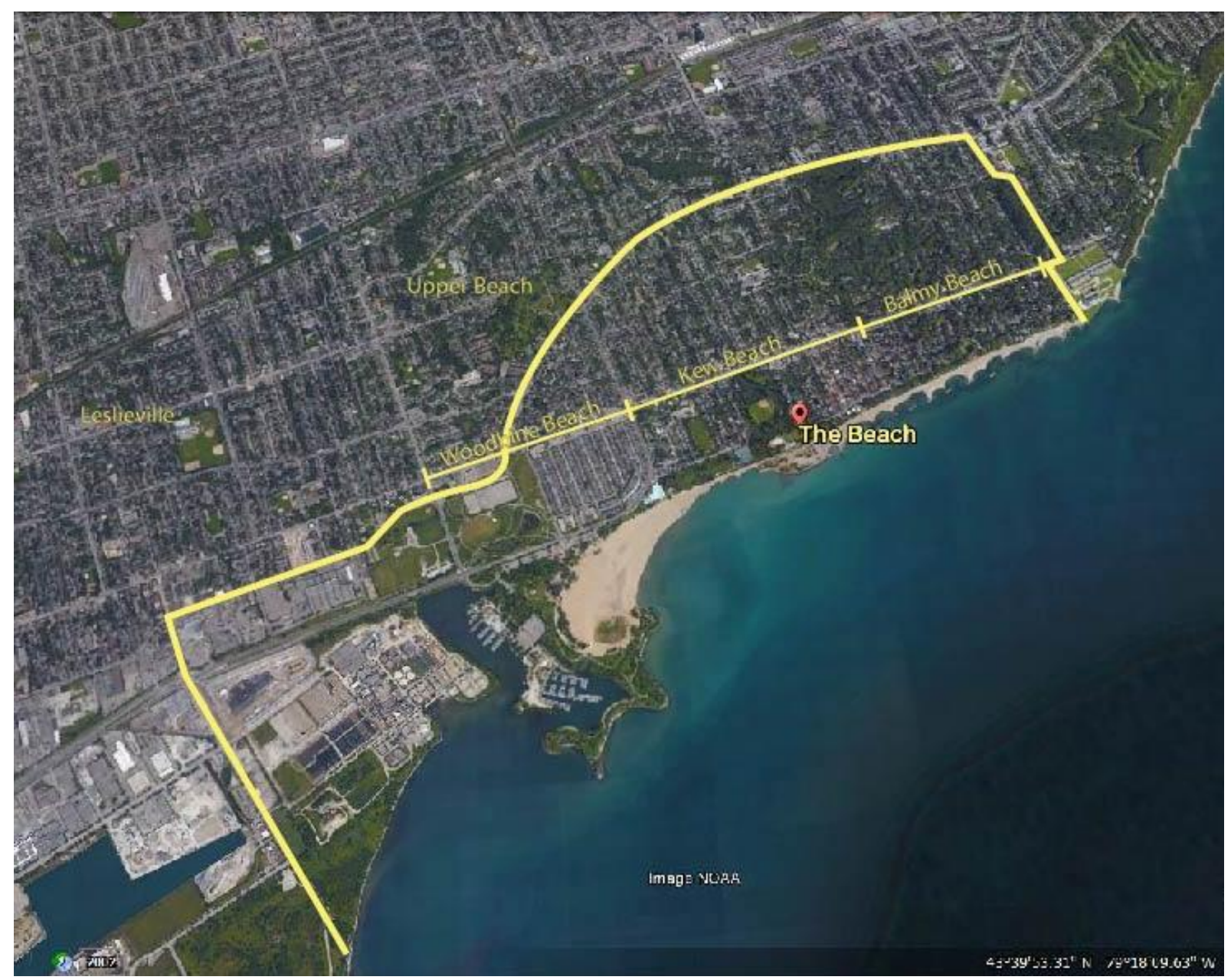

Figure 1: The Beach and its Three Precincts

Source: Google Earth, 2015

Three separate communities have formed in the neighbourhood: Woodbine Beach, Kew Beach, and Balmy Beach (Figure 1) (City of Toronto, 2012 b). After the closing of Greenwood Racetrack in the 1990s, a large five building 5-storey development project was built by Pemberton Group on the south side of Queen Street between Northern Dancer Boulevard and Woodbine Avenue (Armstrong and Armstrong, n.d.). This marked the beginning of major redevelopment in Woodbine Beach, contributing to the emergence of infill development pressure in other more stable areas of the Beach.

\section{POLICY CONTEXT}

There are several relevant plans, policies, and guidelines pertaining to retail on Toronto's main streets. Various higher level planning policies direct retail uses toward major corridors which support socially-diverse and complete communities. By-laws and guidelines consist of more detailed contextspecific requirements regarding the size, shape and aesthetic of buildings on these major corridors. 


\section{Province of Ontario's Growth Plan}

In 2006, the Province of Ontario enacted a plan that would revitalize urban areas, protect Greenfields from urban sprawl, facilitate more housing and transportation options, and establish complete communities. Known as the Growth Plan for the Greater Golden Horseshoe, this Plan attempts to distribute future growth across the region by setting population and employment targets for all settlement areas (2.2.1). In order to meet these intensification targets, the City of Toronto and other municipalities across the province have made land-use policy changes to encourage mid-rise development within urban centres and along major avenues serviced by public transit.

The Plan does not discuss retail development in great detail. However, it suggests that the desired compact urban form should include "efficient use of land, walkable neighbourhoods, mixed land uses, proximity to transit and reduced need for infrastructure" (MPIR, 2006, p. 48). In this case, mixed land uses include residential, retail, office and institutional uses. The Plan also goes into significant detail about the protection and preservation of employment lands by restricting non-employment uses. According to its policies, major retail is not considered an employment use (2.2.6.5) and only associated retail is permitted in employment areas (MPIR, 2006, p. 49) ${ }^{4}$. This policy direction diverts the pressure for new retail development away from employment areas, which can coordinate large format retail. Instead, this retail is pushed toward mixed use areas within the urban boundary where new development faces a myriad of planning challenges and land-use conflicts.

\section{City of Toronto's Official Plan}

The City of Toronto's Official Plan acknowledges that retail development, in form, function and scale, has changed significantly over the last 60 years and will continue to evolve due to changing demographics and other factors. Section 3.5.3 recognises traditional shopping streets as "centres of community activity that add life to adjacent neighborhoods and support a walkable City" (p. 3-44). Public infrastructure improvements and involvement of business associations are also strongly encouraged on these streets (3.5.3.2). The plan suggests that successful retail sectors need to provide a range of shopping options (3.5.3.1) and prioritizes retail along major Avenues (3.5.3.3). Policies regarding new development on traditional retail shopping streets attempt to ensure compatibility with the existing character and uses found in the area. New site and area-specific by-law requirements must address a list of considerations pertaining to small business success, the public realm and building design (3.5.3.4).

\footnotetext{
${ }^{4}$ Definition of employment areas is taken from the Provincial Policy Statement, 2005.
} 
Map 2:Urban Structure and Map 3: Right-of-way Widths of the Official Plan designate Queen Street East ${ }^{5}$ as an Avenue, with a 20 metres width. While transit-supported Avenues are the target of major reurbanization efforts (2.2.3.1), change along these corridors is meant to be incremental. The Official Plan attempts to position Avenues as main streets, facilitating social interaction through appropriate redevelopment and public infrastructure investment (2-17). Although the plan does not formally identify main streets within the city, the City's Streetscape Manual categorizes Queen Street East as an existing main street ${ }^{6}$ (City of Toronto, n.d.).

The City must complete an Avenue Study for each Avenue identified in the Official Plan. This study involves the engagement of a variety of local stakeholders, the identification of opportunities for public investment in community improvements, and the determination of the appropriateness of the existing zoning and regulations within the arterial corridor (2.2.3.2). Since an Avenue Study for Queen Street East has not yet been completed, projects along this corridor have "the potential to set a precedent for the form, scale" and intensity of new development (2.2.3.3). As such, development proposals should address the broader context by identifying impacts on existing public infrastructure and neighbouring sensitive uses (e.g. residential and park uses), as well as on the future development trends in the corridor segment. For a project requiring rezoning, the City Council must conclude that the collective impacts of the development, and similar successive developments, along the segment have no negative implications on the Avenue (2.2.3.3.b).

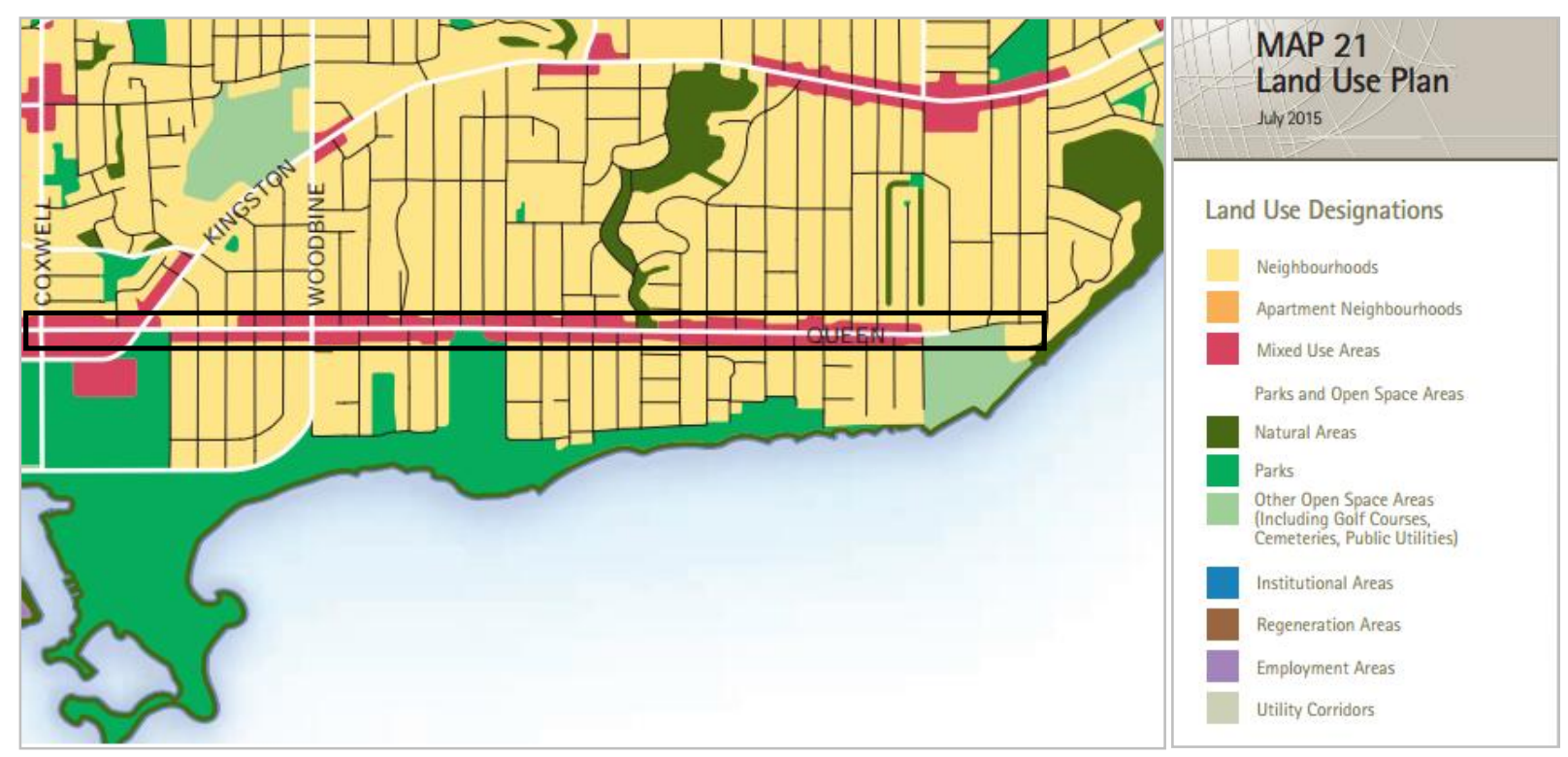

Figure 2: Excerpt of Map 21 of Toronto's Official Plan

\footnotetext{
${ }^{5}$ Between the Don Valley Parkway and Victoria Park Avenue.

${ }^{6}$ Between Lockwood Road and Neville Park Boulevard.
} 
As can be seen in Map 21: Land Use Plan, the Queen Street East corridor in the Beach neighbourhood is primarily designated as Mixed Use Areas with the exception of a few neighbourhood and parks uses along the commercial strip. The Mixed Use Areas designation is very broad; it allows for a variety of different uses including retail and is primarily concerned with the compatibility of land-use form, scale and function. New development in Mixed Use Areas adjacent to neighbourhood and park uses must pay particular attention to building setbacks, stepping down heights, massing and shadow (4.5.2).

Queen Street East ${ }^{7}$ is also identified as a potential Heritage Conservation District in Map 36: Site and Area Specific Policy 305. Though the process of forming a Heritage Conservation District is time consuming, this designation would put significant requirements on where and what kind of development would be appropriate along Queen Street.

\section{City Zoning No. By-law 438-68}

The City of Toronto's Zoning By-law No. 438-68 zones the majority of the properties in along Queen Street in the Beach neighbourhood as Mixed Use District. It permits a maximum total density ranging from 2 to 2.5 and a height of between 10 and 12 metres. The by-law outlines a list of permitted uses including a variety of residential, recreational, cultural, institutional, retail, workshop and office uses (Section 8(1)). While the by-law is not restrictive in the kinds of uses permitted in the corridor, the height and density restrictions limit development to no more than two to three storeys. This means that new applications for mid-rise development, which can be up to 11 storeys tall, must apply for a zoning amendment, and possibly an official plan amendment. Although, the City enacted a new city-wide zoning by-law (569-2013) in 2013, the mixed-use properties along Queen Street still fall within the purview of the old bylaw.

\section{Avenue and Mid-rise Buildings Study}

In 2010, the City of Toronto released the Avenue and Mid-rise Buildings Study in order to guide the accommodation of future growth within the city. The study proposes policies and processes to facilitate the reurbanization of underdeveloped streets designated as Avenues, which transect mixed use, employment, regeneration and institutional areas. It outlines performance standards for new mid-rise development, paying close attention to height, angular plane, building façade, transition to the surrounding neighbourhoods, sidewalk design and streetscape, vehicular access and loading areas, design quality, and development in areas of historical significance. Appendix 2 of the study features a set of retail criteria and principles; the former to determine if retail-commercial uses are appropriate and the

\footnotetext{
${ }^{7}$ Between Coxwell Avenue and Victoria Park Avenue.
} 
latter to provide guidance on facilitating viable retail (Brook McIlroy Planning and Urban Design/Pace Architects, 2010).

Community concerns over the unique character of Queen Street East in Ward 32 prompted the Toronto and East York Community Council to petition its removal from the Avenue and Mid-rise Building Study. City Council carried this motion in July 2010 (Decision 3.a, Item PG. 39.9) (Brook McIlroy Planning and Urban Design/Pace Architects, 2010 b). Since the study's policies were not applicable to Queen Street East, the existing Beach urban design guidelines (originally passed in 1987 and updated in 1991) remained in effect. While the Beach guidelines were context-specific, the community felt that they were out-of-date and misaligned with the policy directions laid out in the new Official Plan (City of Toronto, 2012).

\section{Queen Street East: Coxwell Ave to Nursewood Rd Guidelines ${ }^{8}$ \& City Zoning By-law No. 607-2013}

In 2012, the Toronto and East York Community Council requested the completion of a visioning study by City Planning Division on a 3-kilometre stretch of Queen Street East between Coxwell Avenue and Nursewood Road. Commonly known as the new Beach urban design guidelines, this document was meant to "balance the policies of the Official Plan with the desire of the local community to maintain the existing character [of the street]" (City of Toronto, 2012 b, p. 1). The document includes broad public realm, site organization, massing, heritage and pedestrian amenity guidelines, as well as more specific guidelines for its three precincts: Woodbine Beach, Kew Beach and Balmy Beach. The general guidelines recommend generous 4.8 metre sidewalk widths, 45 degree angular planes, spill out activities (e.g. outdoor cafés), streetscape improvements, improved accessibility, and storefront animation (p. 12). Restaurant uses are strongly encouraged in the guidelines, whereas small independent businesses are preferred because they reinforce the character of the neighbourhood (p.13). According to the guidelines, building façades of new development should incorporate various signage and weather protection activities but design elements like arcades, colonnades and internal malls are discouraged (City of Toronto, 2012 b, p. 15). Some components of the guidelines, including sidewalk width and ground floor height, are enforced by By-law No. 607-201. Although this by-law amends the old City of Toronto By-law (No. 43886), it is also included as a Site and Area Specific Policy (No. 466) in the Official Plan.

While the guidelines encourage smaller businesses along Queen Street, identifying strategies for supporting small independent businesses is outside their scope. Instead, they primarily focus on external aesthetic elements like public realm, streetscape, and building façade. The guidelines also use indirect

\footnotetext{
${ }^{8}$ As of Jan 2016, there has only been one development subject to the new guidelines - a five-storey medical office building at 1895 Queen St E, which is outside the study areas.
} 
design requirements to control the entry of larger chain retailers. For example, ground floor height restrictions are used to inadvertently discourage large commercial unit footprints.

\section{GREY AND PEER-REVIEWED LITERATURE}

The effect of mid-rise development on retail main streets has not been sufficiently addressed in academic and professional literature because mid-rise intensification in North America is a relatively new phenomenon. In Toronto, the shift away from Greenfield development on the periphery in favour of more

centralized infill development is further complicated by the limited availability of land parcels appropriate for high-rise buildings. As a result, mid-rise development outside the downtown core is becoming the newest economically-feasible development trend in the city's inner suburbs. Since this trend has not been adequately investigated in the past, the following section addresses the three main themes of this study separately. These themes include: retail vibrancy, mixed-use development and retail development.

\section{Retail Vibrancy}

There is no widely accepted terminology used to describe the successfulness of retail in academic and professional literature. Three commonly used terms in retail assessment include vibrancy, viability and vitality; however, they are often poorly defined and used interchangeably. Inconsistencies in the use of this terminology and its application make it difficult to comprehensively analyze the body of literature pertaining to retail success.

When describing the success of retail, scholars prefer the terms "viability" and "vitality" (Ravenscroft, 2000; Baker and Wood, 2010; Ratcliffe and Flanagan, 2004). Baker and Wood (2010) make an important distinction between the terms; vitality referring to the amount of foot traffic (or the busyness of the area), and viability meaning the ability to maintain economic sustainability (p. 66). The literature also suggests that these two terms are interdependent (Ravenscroft, 2000), since a substantial customer base generates new investment, and simultaneously, new development attracts more people. Consequently, the evaluation of viability and vitality should be done concurrently with a different set of performance indicators for each.

Scholars often discuss retail viability and vitality in tandem with other themes like citizen participation (Silverman et al, 2008), merchant associations (Bake and Wood, 2010; Sutton, 2010) and business improvement areas (Ratcliffe and Flanagan, 2004). The role these actors play in neighbourhood regeneration contributes to the creation of public realm and local market improvements which facilitate ongoing commercial success. In fact, their long standing connection to a particular area or street makes them an invaluable source of knowledge for community planners and policy makers. 
Another theme in academic literature which is often tied to retail viability and vitality is the role of the traditional main street. ${ }^{9}$ Main streets are usually discussed in terms of a retail hierarchy; they provide retailing and services which support the daily needs of local residents, while larger destination shopping areas (e.g. shopping centres and power centres) cater to the broader region (Buliung and Hernandez, 2009). However, changing land-use patterns and customer behaviour have contributed to the blending of the different levels of the retail hierarchy (Hernandez, 2007; Urban Metrics, 2010).

Carmona (2015, p. 20) identifies a myriad of challenges faced by high streets in London, organizing them into four subgroups: physical fabric (streetscape and building façade), movement (accessibility for pedestrian and vehicular traffic), exchange (building sense of community and place) and real estate (land use types). The article also suggests interventions to address these challenges and stipulates that community engagement, neighbourhood-level management bodies, and local events and activities are essential to improving London's network of high streets (Carmona, 2015).

Similarly, Baker and Wood (2010) also discuss main streets in the context of retail viability and vitality. Unlike Carmona (2015) who evaluates London's high streets at a holistic level, Baker and Wood (2010) use a five-test method to assess the added value of a new retail proposal to the existing retail market. This approach is focused on preserving the retail hierarchy, reinforcing the spatial relationship of existing retail, maintaining a sense of place, facilitating healthy market competition and contributing to a net community benefit (Baker and Wood, 2010, p. 70-72).

All in all, the academic literature explored above is highly diverse. Different disciplinary lenses and scales are employed to explore retail viability and vitality, offering no common terminology or performance measures to assess retail success. While lack of agreement about terminology is also prevalent in professional research and retail guidelines, performance measures are better defined.

Developed by the Department of the Environment, Community and Local Government, Ireland's Guidelines for Planning Authorities Retail Planning (2012) stress the need to balance viability and vitality in town centres. While the guidelines do not define viability or vitality, they list four essential components to maintaining the balance (DECG, 2012, p. 56). Although the components are framed differently they overlap significantly with the ones presented by Carmona (2015): attractions (= real estate), accessibility (= movement), amenity (= physical fabric), and action (= exchange). The guidelines also include twelve health indicators for retail viability and vitality in town centres; the analysis portion of this study is heavily influenced by these indicators.

\footnotetext{
${ }^{9}$ Including "high streets" which is used in the United Kingdom to refer to main streets.
} 
Designed by Streetsense, the DC Vibrant Retail Streets Toolkit (2012) is a policy guideline specifically geared toward retail shopping streets. The toolkit is used to measure the vibrancy of 16 smallscale shopping streets in the northeastern region of the United States and outlines eleven attributes exhibited by most shopping streets. While not every metric is directly relevant to each shopping street, vibrant shopping streets are described as areas which are well managed; designed for retail; diverse in retail offerings; perceived to be safe; championed and invested in; anchored with public or cultural facilities; pedestrian-oriented, unified in character; populated by both local and national brands; accessible using transit and automobiles; and clearly visible (Streetsense, 2015, p.22). Moreover, the toolkit stresses that retail vibrancy is a moving target which is dependent on local context, as well as market conditions. This definition heavily influenced the thinking around the performance measures used for the retail analysis of this study. For simplicity, from hereinafter the term "retail vibrancy" will be used as a blanket term to include retail vibrancy, as well as viability and vitality.

Although the discourse around retail vibrancy is complex and interconnected, there are important similarities in both the academic and professional literature. Retail vibrancy seems to be directly tied to ideologies of traditional main streets and local citizenry involvement. The interplay between these elements is particularly important when introducing new mid-rise development which has its own unique built form and scale.

\section{Mixed-Use Development and Mid-Rise Development}

Mixed-use development emerged in North America in the late $20^{\text {th }}$ century as a response to the growing concern over land use inefficiencies and environmental impacts of separating sensitive residential uses from non-sensitive uses (Grant, 2002). It stemmed from the influential writing of Jane Jacobs, who argues that the mixing of land uses creates vibrant and pedestrian-oriented neighbourhoods (Jacobs, 1691). One of the earliest definitions of “mixed use" was presented in Urban Land Institute's Mixed Use Development Handbook in 1987. It states that a truly mixed use project must have "three or more significant revenue-producing uses" (Witherspoon et al, 1976). While this definition has been widely accepted, the scale, dimensions and characteristics of mixed use have evolved considerably since its creation (Conard, 2010). According to Grant (2002), a Canadian mixed-use development advocate, this kind of development should aim to increase intensity, diversity and integration of different land uses. In turn, mixed-use development has the potential to optimize public infrastructure use, create more housing options, produce social equity, and reduce the need for car-ownership (Grant, 2002).

Nevertheless, mixed-use development faces a few significant application challenges. The first challenge is that current planning ideologies about pedestrian-oriented and compact communities do not 
reflect predominant consumer behaviours in North America (Grant and Perrott, 2011). The continued dominance of suburban living and car ownership in today's modern society has forced many developers to integrate two seemingly different lifestyle approaches. While mixed-use development is meant to support the creation of complete communities (Grant and Perrott, 2011), major shifts in consumer behaviour will be needed to close the gap between planning expectations and societal norms. This is particularly challenging in a winter-climate city like Toronto (Grant, 2002) where the winter-season makes it difficult to maintain consistent levels of vitality.

Mixed-use developers also face major regulatory challenges. They must overcome many obstacles regarding restrictive land-use zoning and unrealistic parking requirements (Macht, 2009). Since mixing uses requires a delicate multiple-phase approach, developers take on more financial risk and plan for longer time horizons, which may be further complicated if ownership of commercial space is retained after completion (Funderburk, 2004). In addition, requirements for retail uses in most new developments has the potential to influence its marketability as there may be an oversupply of retail or insufficient market demand in the neighbourhood (Grant and Perrott, 2011). In fact, developers often have limited inhouse commercial leasing and brokering expertise, requiring the use of specialized external agencies.

Since Toronto's mid-rise guidelines strongly encourage retail uses at grade, the challenges described above extend to mid-rise development. This development is also restricted by its density and scale, which means that it is largely unfeasible outside transit-supported avenues in semi-urban areas (Brown, 2012). Operating in a semi-urban market brings with it a host of obstacles including complicated land assembly, contamination risk, stringent urban form compatibility requirements, and heighten public sensitivity around infill development. Moreover, professional literature suggests that one of the underlying challenges to successful mid-rise development is establishing economies of scale (Brown, 2012). Due to the fact that the size of mid-rise development is restricted to 11 storeys in Toronto, developers have fewer units which they can sell to recuperate the costs of land purchase, municipal approvals and construction. This cost is carried forward to a smaller number of end consumers, potentially affecting the overall affordability of both residential and commercial units (Dalglish, 2014). All things considered, mid-rise development is faced with a myriad of challenges which come from operating in well-established areas within the inner suburbs.

\section{Retail Development}

The majority of peer-reviewed retail development literature originates from the European Union, and the United States. This body of literature is quite extensive, but its primary focus is the evaluation of market conditions using key indicators like property value, property rents, market sales, absorption rates, 
and vacancy rates. While these indicators may have implications for real estate developers and managers, they provide little direction for city planners and policy makers. Nevertheless, the methodological approaches used in retail development literature helped frame the research approach ultimately taken in this study.

One stream of this literature uses a statistically rigorous approach to evaluate a particular quality of a large geographic area(s). This market driven approach tends to assess factors like the impact of accessibility on retail rents (Netzell, 2013) and the interplay between rent prices, vacancy rates and new building stock (Hendershott et al 2013). Since this type of research requires very detailed data, the physical dimension of individual entries can also be used to identify clusters where specific intervention or closer attention in needed. Katyoka and Wyatt (2008) use such an approach to map natural vacancy rates and identify areas where vacancy persists on a long-term basis. They use their findings to recommend areas in Leeds, United Kingdom which could benefit from policy intervention and targeted regeneration efforts. The scale and systematic methodology used in this literature often generates relevant findings and recommendations for both academic and professional audiences.

Another methodology commonly used in retail development literature employs a mixed methods approach to explore the dynamics of retail and the role it plays in the community. Statistical analysis of secondary data and qualitative interviews with stakeholders are used to either compare a small number of geographically-defined areas (Linovski, 2012; Yeates and Montgomery, 1999) or evaluate the impacts of a particular event within a single area (Crosby et al., 2005). The scale at which this research is done can vary quite significantly, from a street segment, to a neighbourhood, and finally to an entire city. Since these findings are usually comparative as opposed to absolute, the implications are context-specific. Consequently, this type of literature identifies implications and suggests areas of further study, as opposed to providing actionable policy recommendations.

The strength of the first approach lies in its ability to identify spatial trends, while the latter approach makes it possible to compare different case studies (geographical or temporal) based on a thorough exploration of the social and economic context of the area. The research approach undertaken here intends to borrow from both of the methodologies presented in order to capture a wider academic and professional audience. 


\section{CHAPTER 2: METHOD}

This study used a mixed methods approach, employing both quantitative and qualitative indicators to analyze the vibrancy of a stable retail area against one which is experiencing signs of ongoing redevelopment (Figure 3). Woodbine Beach Precinct was chosen as the first study area because it has been experiencing mid-rise development pressure since the early 2000s. Given that Kew Beach Precinct has been the commercial centre of the Beach for over a century, it was chosen as the second study area. While Balmy Beach Precinct would also be an appropriate choice, this precinct is more residential in nature and appears to have a smaller catchment area than the other two precincts.

Due to the fact that the Kew Beach Precinct is larger the analysis of the two study areas was limited to 450 metres within each precinct. Hereinafter, all references to "Woodbine Beach" and "Kew Beach" refer to the 450-metre study areas, not the precincts in their entirety. Although, these study areas are quite small and relatively close in proximity, they provide a representative sample of their respective precincts and their customer base does not appear to significantly overlap.

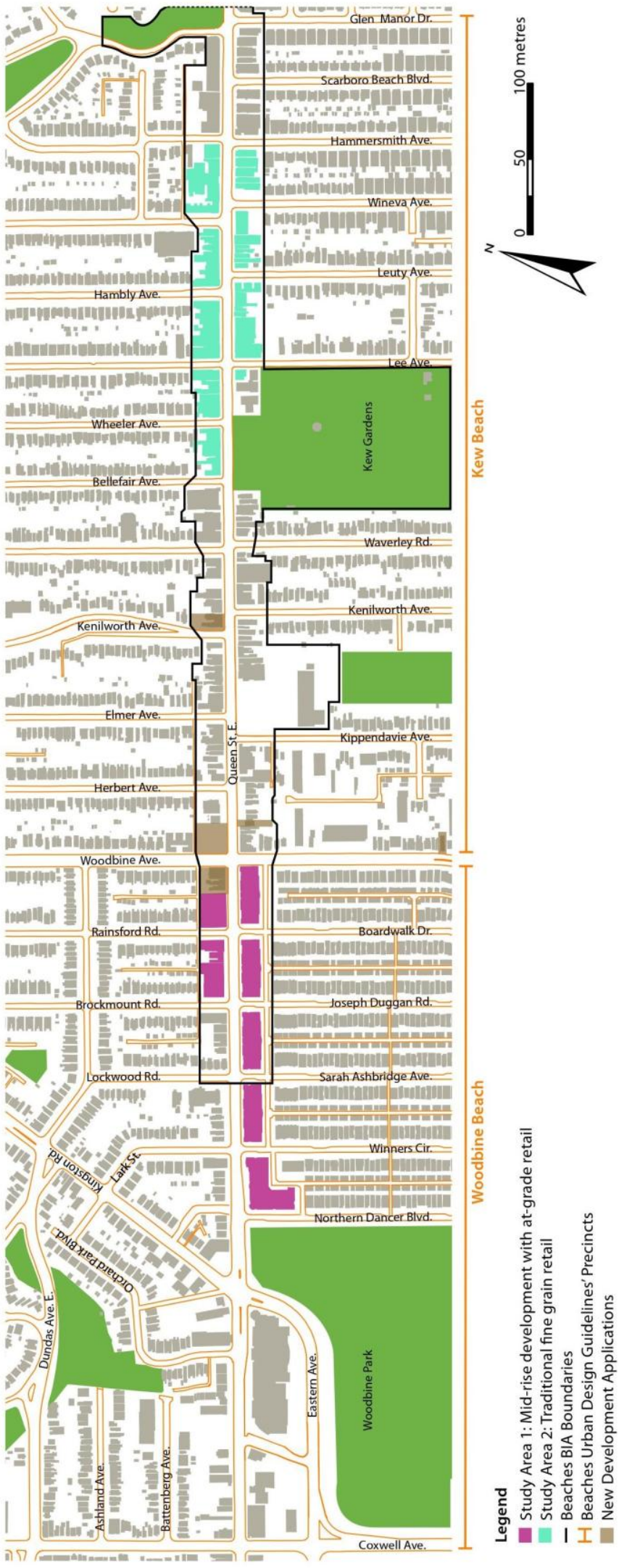

Figure 3: Map of Study Areas 
Study area boundaries encompass the mid-rise development on Queen Street East between Kingston Northern Dancer Boulevard and Woodbine Avenue, as well as the fine grain retail between Bellefair Avenue and Hammersmith Avenue (Figure 3). When defining these spatial boundaries, an attempt was made to limit the amount of active construction sites in order to maximize the total number of operational retail units within the study. However, redevelopment on the northwest corner of Woodbine and Queen began shortly after the boundaries for the research study were finalized. ${ }^{10}$ Moreover, corner lots in the study areas may have retail and other commercial establishments fronting on to a north-south side road. These properties were not included in the analysis, as data was only collected for retail properties fronting onto Queen Street. Like mentioned earlier, major parts of the Woodbine Beach Precinct are less than 10 years old which also limited the longitudinal aspect of the analysis. ${ }^{11}$

As can be observed in Figure 3, the two study areas are largely within the Beach Village Business Improvement Area (BIA). Ontario's BIAs play a pivotal role in defining district boundaries, recruiting new businesses, attracting visitors and shoppers, hosting special events, and advocating and lobbying the collective interests of its members (Government of Ontario, 2010). In North America, BIAs are particularly concerned with issues of consumer marketing, landscaping, and beautification of publically accessible space (Hoyt, 2003; Mitchell, 2001). They have also been credited with decreasing crime rates (Hoyt, 2005) and increasing property values within the immediate area (Ellen, Schwartz and Voicu, 2007). The role of the Beach Village BIA will be discussed in greater detail in Chapter 3: Problem Investigation.

\section{THE APPROACH}

Given that there is no widely accepted evaluation approach for measuring retail vibrancy, a hybrid approach was used to assess and compare the two study areas. The retail analysis of Woodbine Beach and Kew Beach was primarily based on the retail health indicators in Ireland's Guidelines for Planning Authorities Retail Planning and the building blocks of a vibrant street in DC's Vibrant Retail Streets Toolkit. The indicators and performance measures used in the retail analysis are listed in Table 1.

\footnotetext{
${ }^{10}$ Demolition on the northwest corner of Woodbine Ave began in December 2015, and at the time of the CSCA survey 2 of the 4 stores were still occupied.

${ }^{11}$ It appears that there was a delay between when some of the buildings were built and when CSCA began keeping records on them. The majority of the south side of Queen was built up in 2003, but records for these buildings only date back to 2011 .
} 
Table 1: Health Indicators of Retail Vibrancy

\begin{tabular}{|c|c|c|c|}
\hline Indicator & Type & Source & Performance Measures \\
\hline $\begin{array}{l}\text { 1. Retail } \\
\text { Competitiveness }\end{array}$ & Quantitative & $\begin{array}{l}\text { - CSCA } \\
\text { - Toronto Property Data Maps }\end{array}$ & - Distribution of retail mix \\
\hline $\begin{array}{l}\text { 2. Diversity of } \\
\text { Retail Sizes }\end{array}$ & Quantitative & $\begin{array}{l}\text { - CSCA } \\
\text { - Toronto Property Data Maps }\end{array}$ & - Distribution of retail unit sizes \\
\hline $\begin{array}{l}\text { 3. Proportion of } \\
\text { Vacant } \\
\text { Properties }\end{array}$ & Quantitative & $\begin{array}{l}\text { - Field Observations } \\
\text { - CSCA } \\
\text { - Toronto Property Data Maps } \\
\text { - City of Toronto BIA summaries }\end{array}$ & $\begin{array}{l}\text { - Vacancy rate } \\
\text { - Persistent vacancy rate }\end{array}$ \\
\hline 4. Retail Rents & Qualitative & $\begin{array}{l}\text { - Field Observations (Note: } \\
\text { market rent data would be more } \\
\text { appropriate here) }\end{array}$ & - Owned versus leased retail units \\
\hline $\begin{array}{l}\text { 5. Retail } \\
\text { Representation } \\
\text { \& New Policy } \\
\text { Directions }\end{array}$ & $\begin{array}{l}\text { Quantitative } \\
\& \\
\text { Qualitative }\end{array}$ & $\begin{array}{l}\text { - CSCA } \\
\text { - City-led policies, by-laws and } \\
\text { studies }\end{array}$ & $\begin{array}{l}\text { - Retail versus service uses } \\
\text { - "Mom and pop" versus big chain } \\
\text { retailers } \\
\text { - Policy directions affecting } \\
\text { neighbourhood retail trends }\end{array}$ \\
\hline 6. Public Realm & Qualitative & - Field Observations & $\begin{array}{l}\text { - Quality and quantity of landscaping, } \\
\text { street furniture and signage } \\
\text { - Presence of storefront animation, } \\
\text { patios and outdoor cafés }\end{array}$ \\
\hline $\begin{array}{l}7 . \\
\text { Environmental } \\
\text { Quality }\end{array}$ & Qualitative & $\begin{array}{l}\text { - Field Observations } \\
\text { - Toronto Interactive Map }\end{array}$ & $\begin{array}{l}\text { - Presence of community-based } \\
\text { beatification } \\
\text { - Absence of graffiti and garbage } \\
\text { - Proximity to public institutions, parks } \\
\text { and open space (at } 100 \text { metre buffer) }\end{array}$ \\
\hline 8. Accessibility & $\begin{array}{l}\text { Quantitative } \\
\& \\
\text { Qualitative }\end{array}$ & $\begin{array}{l}\text { - Field Observations } \\
\text { - Toronto Interactive Map } \\
\text { - Walk, Transit and Bike Score }\end{array}$ & $\begin{array}{l}\text { - Quality of pedestrian, transit, and } \\
\text { bike access based on Walkscore.ca } \\
\text { - Vehicular access } \\
\text { - Quality and quantity of parking }\end{array}$ \\
\hline $\begin{array}{l}\text { 9. Customer } \\
\text { Views \& } \\
\text { Behaviour }\end{array}$ & Qualitative & $\begin{array}{l}\text { - Field Observations (Note: } \\
\text { consumer surveys would be more } \\
\text { appropriate here) }\end{array}$ & - Types and location of trips made \\
\hline $\begin{array}{l}\text { 10. Traffic } \\
\text { Flows }\end{array}$ & Qualitative & $\begin{array}{l}\text { - Field Observations (Note: traffic } \\
\text { count studies would be more } \\
\text { appropriate here) }\end{array}$ & $\begin{array}{l}\text { - Relative volume of traffic } \\
\text { (pedestrian, bike, transit and vehicle) }\end{array}$ \\
\hline $\begin{array}{l}\text { 11. Safety } \\
\text { \&Occurrence of } \\
\text { Crime }\end{array}$ & Quantitative & $\begin{array}{l}\text { - Field Observations } \\
\text { - Toronto Police Services } \\
\text { Statistics }\end{array}$ & - Neighbourhood crime rates \\
\hline $\begin{array}{l}12 . \\
\text { Socioeconomic } \\
\text { Demographics } \\
\text { of Local } \\
\text { Residents }\end{array}$ & Quantitative & - Census 2011 & $\begin{array}{l}\text { - Demographic Ring Study } \\
\text { (population, education attainment, } \\
\text { household income etc.) }\end{array}$ \\
\hline
\end{tabular}

Note: All indicators were informed by stakeholder interviews to some degree

Source: Based on "Vitality and Viability Health Check Indicators" in Ireland's Guidelines for Planning Authorities Retail Planning, 2012, p.57-58 and the "Elements of a Vibrant Street" in DC Vibrant Retail Streets Toolkit, 2012, p. $18-21$. 
Ireland's retail planning guidelines offer a solid list of twelve health indicators which can be used to measure town centre vitality and viability. While these indicators are not directly designed for main street retail, the methodology proposed in the analysis is broad enough to be applied to a variety of commercial areas (DECG, 2012). Eleven of the twelve health indicators ${ }^{12}$ were adopted for the analysis of retail in Woodbine Beach and Kew Beach (See Table 1). However, these guidelines do not provide a detailed list of performance measures which could be used to comprehensively evaluate each indicator.

The DC Vibrant Retail Streets Toolkit was used to supplement Ireland's guidelines, as it provides a list of comprehensive metrics for evaluating shopping streets in the United States (Streetsense, 2012). Since the metrics (specifically pertaining to market conditions, mix and types of uses, and accessibility features) can be more broadly applied to other commercial streets, they were included as performance measures in this retail analysis (See Table 1). It is important to note that the performance measures chosen reflect the data availability as well as the resource and time constraints of this study. Future and more comprehensive studies on retail vibrancy may choose to employ more complex performance measures, possibly incorporating more multifaceted statistical analysis.

\section{THE DATA}

A combination of quantitative and qualitative data was collected for this retail analysis. Secondary quantitative data was collected from a variety of sources, such as the Centre for the Study of Commercial Activity, Census 2011 and websites like Toronto.ca, Walkscore.com and CBC.ca. While this data was used as the backbone for the analysis, acquiring quantitative information was not feasible or practical for every performance measure. Consequently, primary qualitative data, including field observations and interviews with key stakeholders, was used to provide context for the quantitative findings and fill potential information gaps. While qualitative data could only be used to explain the relative performance of the two study areas to each other, it revealed several interesting themes and trends outlined in Chapter 4: Discussion and Recommendations.

The Centre for the Study of Commercial Activity at Ryerson University tracks retail store data for the Greater Toronto Area on an annual basis. Records contain detailed information regarding the retail space (e.g. type of unit, floor area, address and postal code) and its current tenant (e.g. company name, NAICS 3 and 6 digit codes) (CSCA, 2015). CSCA provided records dating back to 1999 on commercial properties between Kingston Road and Glen Manor Drive. This data was coded and analyzed to compare

\footnotetext{
12 "Commercial yields on non-domestic property" was excluded as a health indicator because it was outside of the scope of the analysis.
} 
the two study areas in terms of their retail mix, unit size, distribution, and vacancy rate. Due to the fact that most of the development within the Woodbine Beach Precinct is relatively recent, the analysis was primarily focused on the five year period between 2011 and 2015.

While this data set is quite extensive, providing information which is not available elsewhere, it has a number of limitations. Firstly, the data is usually collected through field surveys during the months of July and August. This time of year is particularly busy in the Beach due to summer tourism and various community events like the Jazz Fest and Rib Fest. This additional customer base helps businesses thrive during the summer, contributing to lower vacancy rates than can be observed during the slower winter season. These field surveys also involve estimations for certain categories (e.g. unit size), which creates the potential for inaccuracy and limits the ability to capture the context of certain spaces. For example, the commercial space in the newest mid-rise development in Woodbine Beach was coded as a single unit even though the by-law amendment for this site requires the 925 square-metre retail space to be filled with three distinct tenants which have a floor area of no larger than 325 square metres each (City of Toronto, 2009). ${ }^{13}$ There is also the potential for missed or inaccurate records due to human error. In the context of this study, it appears that second-storey businesses as well as smaller businesses with less prominent signage were sometimes missed. ${ }^{14}$

Census 2011 and CBC Crime Maps were used to provide information on crime occurrences in the neighbourhood and demographics of local residents, respectively. While these two sources are both dated by approximately five years, they are all that is currently available. Due to the Government of Canada's use of the voluntary National Household Survey in place of the mandatory Long-Form Census in 2011, some of the census statistics may not be fully accurate or representative of the population. Similarly, many of the crime occurrence entries in the City of Toronto have no geographical information which means they were not assigned to a specific neighbourhood (Friesen and Rajagopalan, n.d.). This deflates the number of crimes observed at the neighborhood level, which could potentially distort the findings when comparing different neighbourhoods.

The quantitative data was supplemented with field observations. Between January and March 2016, photographs and notes were taken to document observations and findings (See Appendix 4 for photos of study areas). Since field visits were made during the winter, they do not provide a complete picture of what the study areas are like during the high-volume summer season. As a result, qualitative

\footnotetext{
${ }^{13} 1864$-1876 Queen St E on the northeast corner of Rainsford Road and Queen Street.

${ }^{14}$ At least 2 retail units appear to be missing from the dataset.
} 
semi-structured interviews with key stakeholders were used to gain a more thorough understanding of the neighbourhood.

Retail tenants, retail property owners, commercial real estate agents, the Beach Village BIA and community planners at the City of Toronto were identified as key stakeholders. Unfortunately contact information for property owners was more difficult to acquire than had been anticipated, as such only the other four categories of stakeholders where contacted. An effort was made to include a representation of all stakeholder groups, from both study areas. Since community planners and BIA administrators are not tied to a particular part of the Beach neighbourhood and work more broadly within the area, participants were recruited based on availability.

A total of 6 interviews were conducted during late February and March of 2016. Each interview took about 20 to 30 minutes; interviewees were asked approximately 10 open-ended questions regarding their experience in the Beach neighbourhood. Real estate agents and retail tenants were asked to talk about their business, their satisfaction with the neighbourhood and their general observations regarding retail trends and issues in the area. Community planners and BIA administrators were asked more general questions about their experience or perception of the vibrancy of retail in the Beach (See Appendix 2 for Stakeholder Questions). These stakeholders also provided important insights about the evolution of the social, economic and political contexts of the neighbourhood and what effect these have had on retail development.

Some of the data collected lent itself to being represented visually. Tools like Toronto's Interactive Map Tool as well as Toronto's Property Data GIS files were used to build maps for certain performance measures, regarding retail competitiveness, retail diversity, public realm and accessibility. These visual representations helped identify spatial clusters and trends which would be difficult to uncover using conventional methods of analysis. 


\section{CHAPTER 3: HEALTH INDICATORS OF RETAIL VIBRANCY}

This chapter uses the Health Indicators of Retail Vibrancy (Table 1 of Chapter 2) to describe, analyze and compare retail vibrancy in Woodbine Beach and Kew Beach. The basis of this retail analysis involves a combination of quantitative and qualitative performance measures representing these twelve indicators ${ }^{15}$. The retail store data provided by the CSCA is primarily used to compare the retail competitiveness, retail diversity and retail vacancy within the two study areas. Field observations and other data, including Census 2011, CBC Crime Maps and Walk Score, are employed to analyze the rest of the indicators. Themes and ideas raised during interviews with key stakeholders are also discussed throughout to further supplement the findings.

\section{RETAIL COMPETITIVENESS}

While no single retail mix is suitable for all districts, retail competitiveness is one of the most important components of retail vibrancy (J.C. Williams Group, 2015). Unlike large-format destination centres which cater to a regional market providing specialized retail offerings, main streets are dominated by convenience-type retail which addresses the needs of local residents. In order to achieve retail competitiveness a main street must maintain a suitable quantity and quality of retail options. In turn, increased competitiveness facilitates vibrant streetscapes through storefront animation and improves retail sector efficiency at the neighbourhood level (J.C. Williams Group, 2015).

To evaluate retail competitiveness, it is first necessary to look at the total number of available retail units within the two study areas. The total number of units has been steadily rising due to infill development and conversions of former institutional and residential buildings to accommodate retail and service uses. Between 2005 and 2015, the total number of retail units rose from 20 to 40 in Woodbine Beach and from 54 to 74 in Kew Beach (See Appendix 1). While both study areas are approximately 450 metres in length, the density of retail units in Kew Beach is nearly double that of Woodbine Beach. This suggests that retail along Kew Beach is much more compact, exhibiting smaller frontage widths and preserving a much more pedestrian-oriented scale.

Due to the provincial policy expectation that development along major transit corridors facilitates the creation of complete and compact communities (MPIR, 2006), understanding the type of retail which supports these kinds of communities becomes important. The TOcore Retail and Service Commercial Land Use Study identifies six essential retail categories which facilitate the creation of complete

\footnotetext{
${ }^{15}$ Due to limited information about four of the health indicators, two sets of indicators were combined in this retail analysis, decreasing the total number of indicators from 12 to 10 .
} 
communities (J.C. Williams Group, 2015, p. 32). While these categories reflect the context of Toronto's downtown, they can be applied more generally to any main street retail areas catering to local retail and service needs.

Table 2: Number of Commercial Tenants in Retail Categories which Support Complete Communities, 2015

\begin{tabular}{|lcc|}
\hline & Woodbine Beach & Kew Beach \\
\hline Food and beverage & 2 & 3 \\
\hline Pharmacy and personal care stores & 0 & 1 \\
\hline Personal care services & 1 & 1 \\
\hline Hardware stores & 4 & 8 \\
\hline Food services & 0 & 0 \\
\hline Total & 6 & 18 \\
\hline Percentage of All Retail Units* & $\mathbf{1 3}$ & $\mathbf{3 1}$ \\
\hline
\end{tabular}

* Not including vacant retail units

Source: TOcore Retail and Service Commercial Land Use Study, 2015. Based on the "Downtown Retail Locations that Help to Create Complete Communities" categories on p. 32.

Data Source: CSCA, 2015.

Table 2 shows the quantity of retail units in the two study areas which support complete communities, based on TOCore's retail categories. On the whole, Kew Beach out performs Woodbine Beach in both the number of retail categories it features and the overall variety in its retail offerings. In fact, Kew Beach is generally more focused on local needs as almost 50 percent of its retail supports complete communities, as defined by TOcore.

Not surprisingly, food services overwhelmingly dominate the retail offerings in both study areas. The need for restaurant and café variety is important to a neighbourhood because these services are often highly specialized, catering to only a subset of customer preferences. In addition, most restaurants have similar peak hours of business (e.g. lunch and dinner time); therefore, the total neighbourhood capacity of such establishments must adequately respond to the peaks and valleys of the local market demand.

Both study areas also feature food and beverage establishments, commonly referred to as grocery stores. While their size and quality will not be comprehensively analyzed here, it should be noted that the current floor areas of these businesses limit their product variety. These establishments offer higher-end and specialized food products, meaning that they play a supplementary role to the larger format grocery stores on Gerrard Street and Victoria Park Avenue. In fact, one interviewee confirmed this finding and identified food affordability as a key challenge for the neighbourhood. Although it may be out of scope for this study, food establishment size as it relates to variety and affordability is an important area for future research. 
Table 2 also suggests that neither of the study areas include a hardware store during the 2015 survey; however, it appears that "Beach Hardware" at 2215 Queen St in Kew Beach has been missed in the survey. There are also several other hardware stores, pharmacy and personal care stores, and specialty food stores directly outside the Kew Beach study area, but still within the Kew Beach Precinct. In summation, there is significant evidence to conclude that retail in Kew Beach is more supportive of local retail and service needs than Woodbine Beach.

Table 3: Retail Mix in Woodbine Beach and Kew Beach, 2015

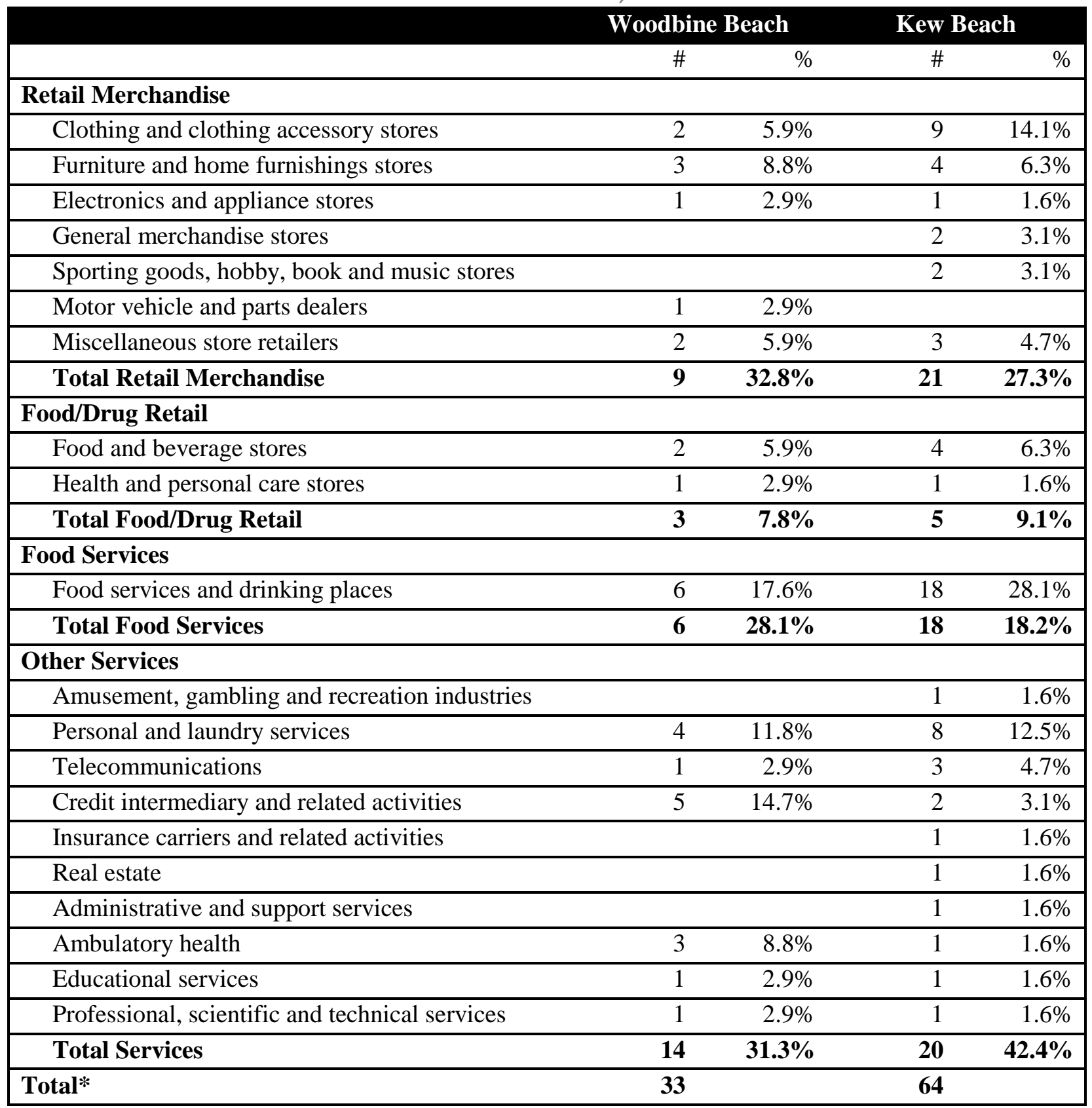

* Not including vacant retail units

Data Source: CSCA, 2015 and based on the North American Industry Classification System. 
While catering to the core local needs is important, the Beach also offers a variety of other retail and service types. Table 3 shows the retail mix based on 20 of the North American Industry Classification System categories found within the study areas. In absolute terms, Kew Beach outperforms or matches Woodbine Beach in every category except ambulatory health, credit intermediary and related activities, and motor vehicle and part dealers. This difference is particularly significant in three retail categories: clothing and clothing accessory stores, food services and drink places, and personal and laundry services. These kinds of retail uses attract high volumes of foot traffic and provide visitors with the opportunity to accomplish multiple errands in a single trip.

Furthermore Table 3 also shows a much narrower distribution of retail types in Woodbine Beach, where six retail merchandise and service categories are not represented at all. It is assumed that the retail mix, and in turn the retail competitiveness, generally improve when the amount of filled units increases; however, this may not always be the case. As one interviewee revealed, when a single company owns many different properties in the same area, potential tenants may seek special covenants in leasing agreements to limit the amount of direct competition. While this is primarily a challenge for retail plazas, which are often owned entirely by the same company, mid-rise developers may experience similar challenges if they opt to retain ownership and lease the retail space. This finding suggests that ownership structure could potentially limit the retail competitiveness of a reurbanizing main street.

A spatial representation of the retail mix, provided in Figure 4, also reveals several interesting findings. While it appears that clustering of similar retail uses is very common in Kew Beach, the small number of retail units in Woodbine Beach makes it difficult to identify retail trends without cautioning that these may be purely coincidental.

When comparing retail on the north and south side of Queen Street East, a few minor trends in Woodbine Beach are apparent. The south side of the street has a slightly higher representation of furniture, appliance and electronics stores, and personal health and beauty services; in contrast, the north side contains most of the study area's food services and stores. Food establishments may prefer the north side of the street due to the fact that higher sun exposure attracts more pedestrians and facilitates a comfortable environment for patios and other spill out activities. Moreover a key stakeholder revealed that retail units on the south side of the street are not equipped with full ventilation systems. This has impacted the representation of restaurant and café uses in these units as only light-prep food services can be accommodated.

Likewise, interviews also revealed that absence of other retail amenities, such as loading areas, pick up areas, and patio space, also limit the functionality of the neighbourhood's retail units. Many 
restaurants and cafés in Kew Beach are not universally accessible because narrow and multi-level floor plans impede access for people with wheelchairs or strollers. For instance, restroom facilities below grade are fairly common in Kew Beach. While the internal layout, design and functionality of retail space cannot be mandated in city-wide policies and guidelines (J.C. Williams Group, 2015 b), mid-rise developers should carefully consider these elements during planning and design stages of development.

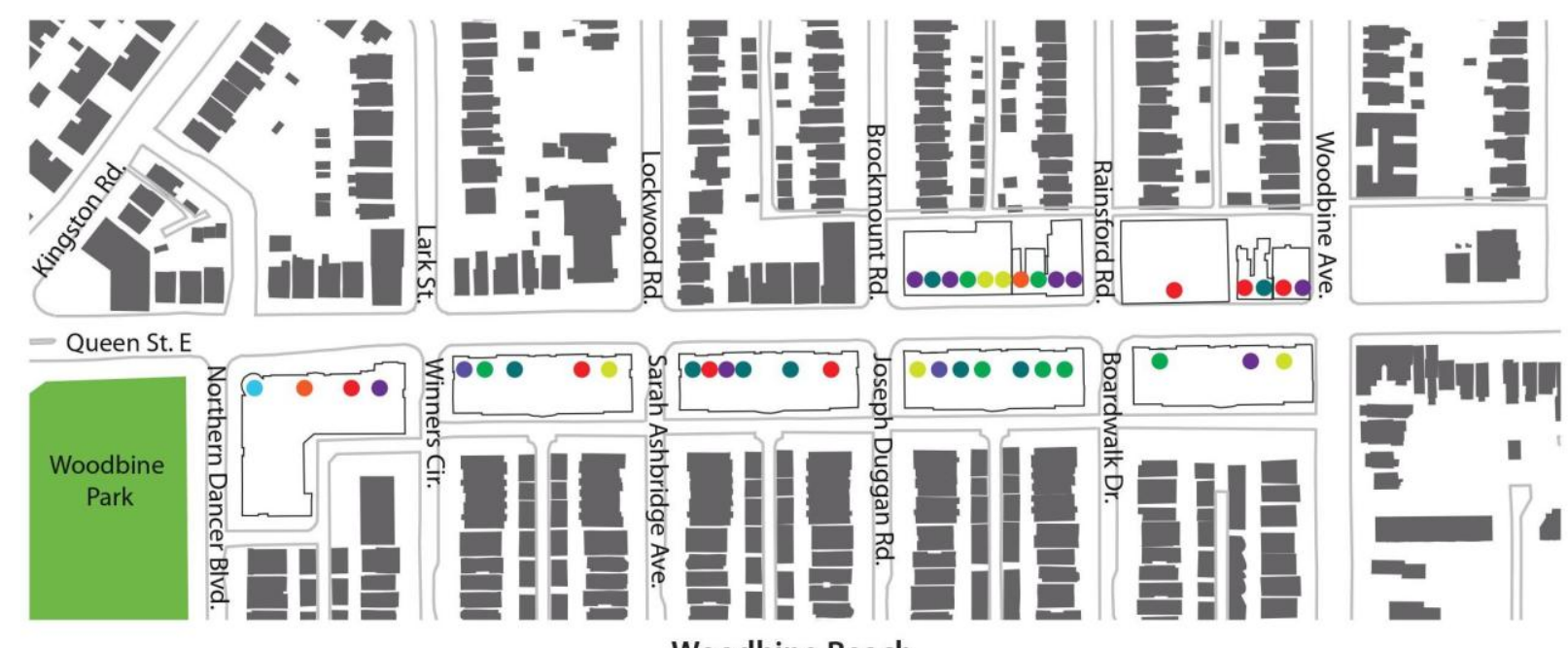

\section{Woodbine Beach}
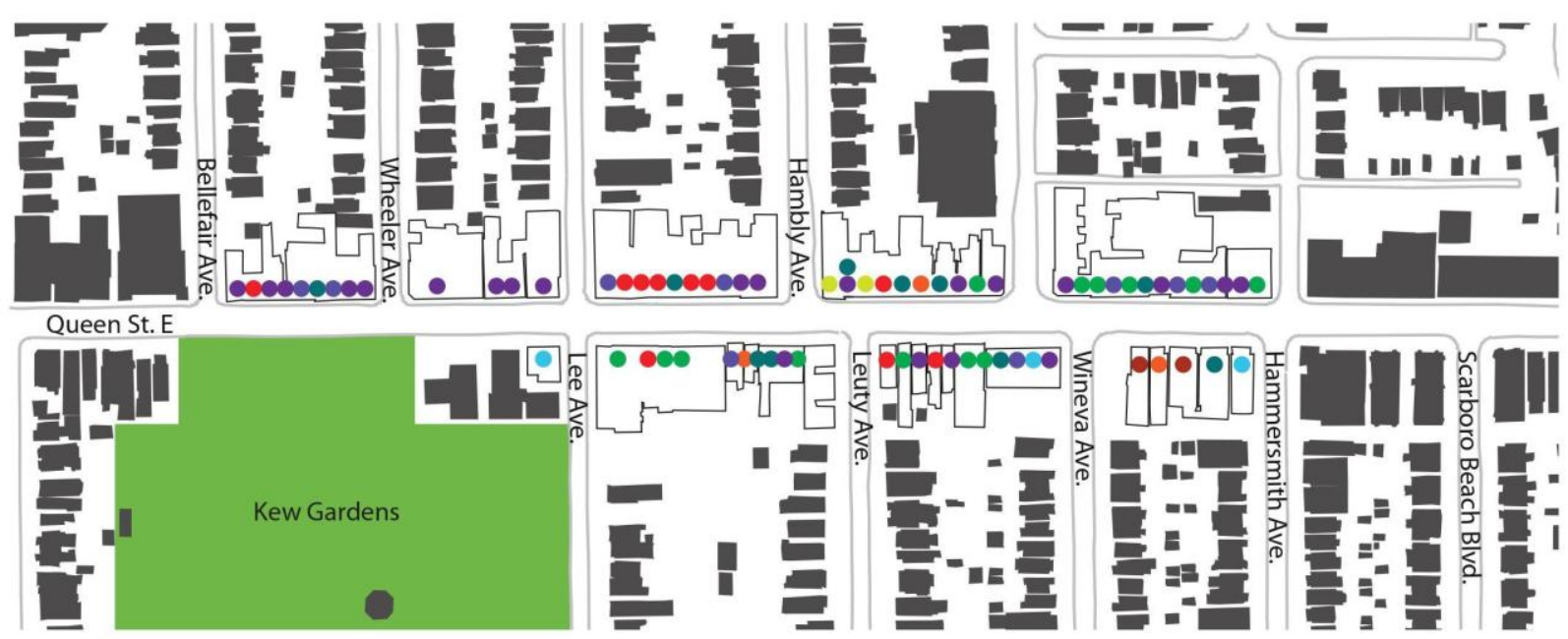

Legend

Food services and stores

Clothing and accessories

Personal health and beauty

Kew Beach

Amusement, recreation, sports, music and otehr hobbies

Furniture, appliances, electronics and other misc. stores

Banking and credit services

Administrative, educational, professional and other services

Insurance and real estate services

Vacant

Figure 4: Spatial Distribution of Retail Mix, 2015

Data Source: CSCA, 2015.

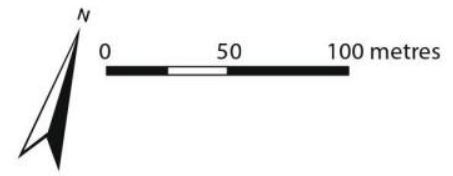


Figure 4 also reveals that Woodbine Beach has a relatively high share of banking and credit related operations. While banks can be an important amenity in a community, their large size and poor storefront animation does not contribute to the vibrant character of the Beach neighbourhood. Moreover, banks and credit establishments have a limited draw of customers and generate less regular foot traffic than other retail and service uses. As can be seen in Figure 4, three of the five bank and credit related businesses in Woodbine Beach are situated in highly-visible corner lot units that would be better suited for other retail uses which animate the street and attract customers.

On the other hand, the corner lots of Kew Beach are dominated by food services and stores, which attract customers throughout the day. There is also a large cluster of food and clothing uses between Bellefair Avenue and Lee Avenue (Figure 4). Kew Gardens, Beach Public Library and Kew Beach Junior Public School are important neighbourhood anchors, which facilitate a strong draw of visitors to this area. There is a second cluster of retail tenants on the north side of Queen Street between Wineva Avenue and Hammersmith Avenue, which caters to a particularly distinct customer base. Observations during site visits revealed that this part of the strip is susceptible to trendy commercial tenants like tobacco and hookah stores, wine bars, and even a brand new medical marijuana dispensary.

The growing number of new development applications and redevelopments in the neighbourhood suggests that both precincts are going through a transition. This trend has created temporary vacancies within the Beach as retail tenants react to changing real estate offerings along the commercial strip. In Woodbine Beach, the northwest corner of Woodbine and Queen has been completely vacated since October 2015, to make way for a new development. Similarly, relatively new real estate just west of Bellefair Avenue has captured a few large tenants, mainly Shoppers Drug Mart and the LCBO, away from Queen Street between Lee Avenue and Hambly Avenue. This has resulted in a cluster of vacancies within Kew Beach, as illustrated in Figure 4.

Indicator Summary: The findings above conclude that Kew Beach has a higher degree of retail competitiveness than Woodbine Beach. Kew Beach not only caters to a high proportion of local retail merchandise and service needs, it also provides significant diversity in other retail offerings. Moreover, several clear retail clusters have formed in the neighbourhood, further reinforcing a heightened level of competition between retail tenants.

\section{DIVERSITY OF RETAIL SIZES}

The variety of retail sizes within a commercial strip influences its retail health because this diversity attracts a wide array of retail tenants and uses. Since traditional fine grain retail is commonly 
dominated by a series of small and narrow retail units, these areas tend to provide a large quantity of smaller units. The existing characteristics of the built form make market entry for larger retailers more difficult; this inherently preserves the economic viability of "mom and pop" stores, who may otherwise be pushed out by larger chains (J.C. Williams Group, 2014).

On the other hand, new mid-rise development offers more flexibility in retail size since at grade retail spaces can be customized based on the needs of retail tenants using breakout panels. Given that mid-rise developers often retain ownership of their retail, they favour larger and more established retail tenants because these tenants are more financially stable and pose less risk (Schabas, 2012). While there is no ideal mix of retail sizes on main streets, size has a significant influence on the types of retail tenants which are attracted to the space.

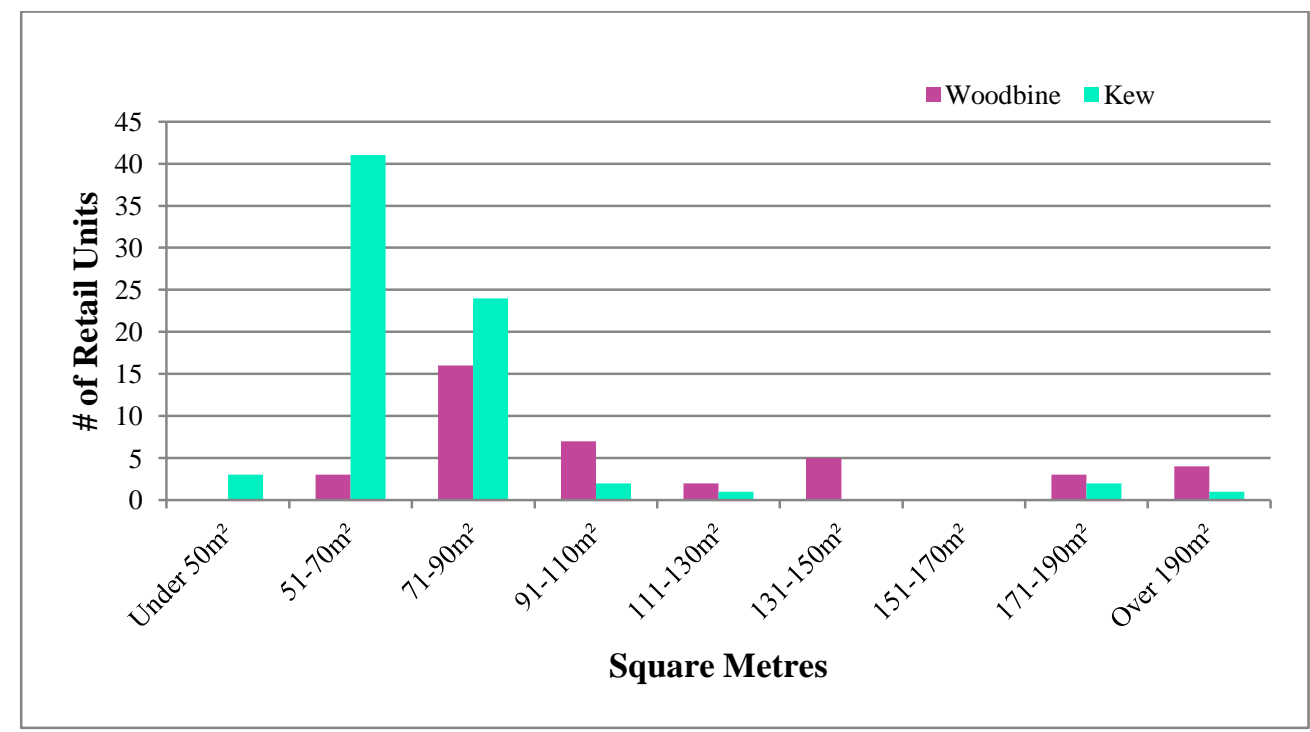

Figure 5: Retail Unit Size based on Square Metres, 2015

Data Source: CSCA, 2015

As can be seen in Figure 5, the majority of Kew Beach's retail units range between 51 and 90 square metres; this is a very typical range for fine grain retail. In contrast, the retail size distribution in Woodbine Beach is a lot more dispersed and most of the units are between 71 and 110 square metres. Although Woodbine Beach has a wider range of retail size options, its total number of units is significantly smaller, thus limiting the amount of choice within the area. Moreover, due to recent redevelopment pressure some of the existing smaller scale retail at the Woodbine and Queen intersection is getting displaced.

The largest retail unit in Woodbine Beach (557 square metres - furniture store) is nearly double the largest unit in the Kew Beach (314 square metres - vacant); this supports the assumption that new mid-rise development in the Beach is better at accommodating larger retail tenants. However, an 
interviewee familiar with the Beach real estate market suggested that the neighborhood does not experience enough through-traffic to attract large chain retailers, and thus these larger retail units are not marketable. This means that property owners of mid-rise commercial space in the Beach may need to readjust their expectations regarding the characteristics (e.g. size and financial stability) of their retail tenants. Certain real estate agents in the Beach have already begun doing this by seeking out existing smaller businesses in the neighbourhood who are looking to relocate.

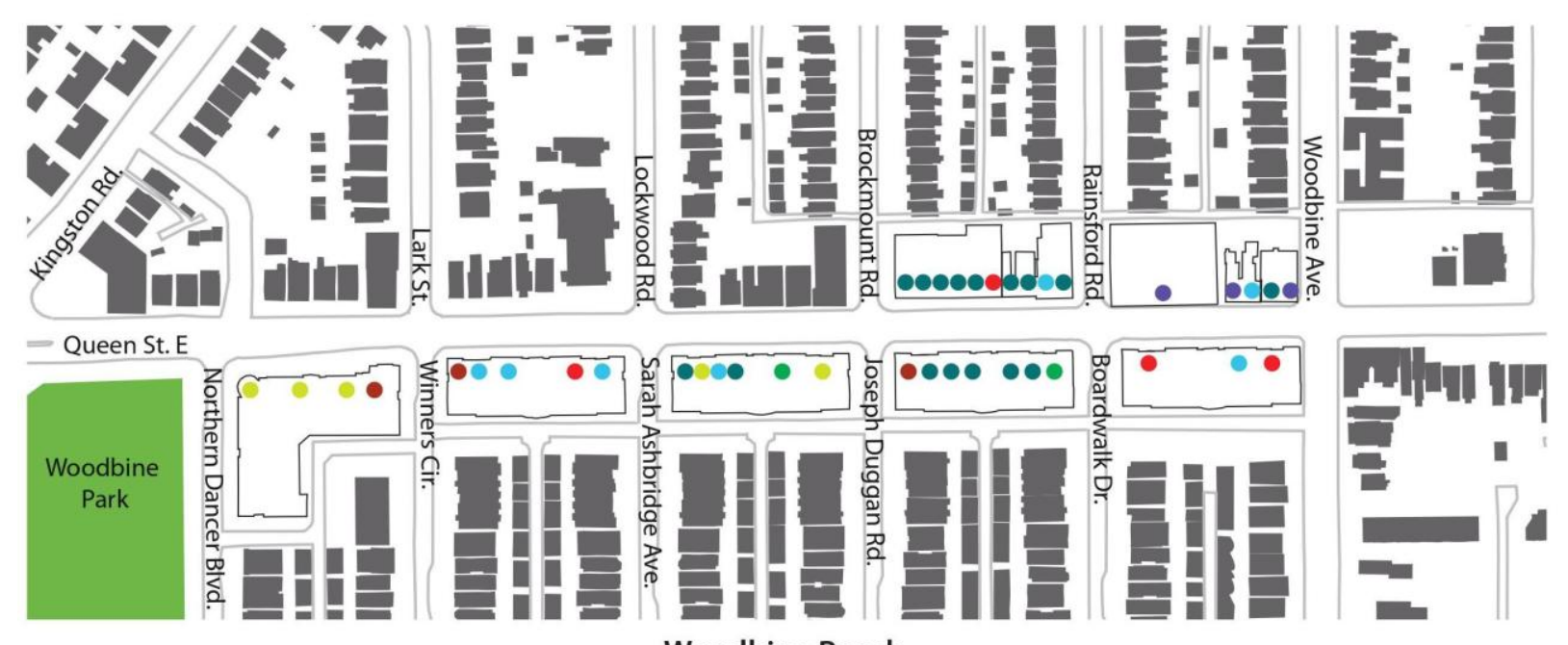

Woodbine Beach
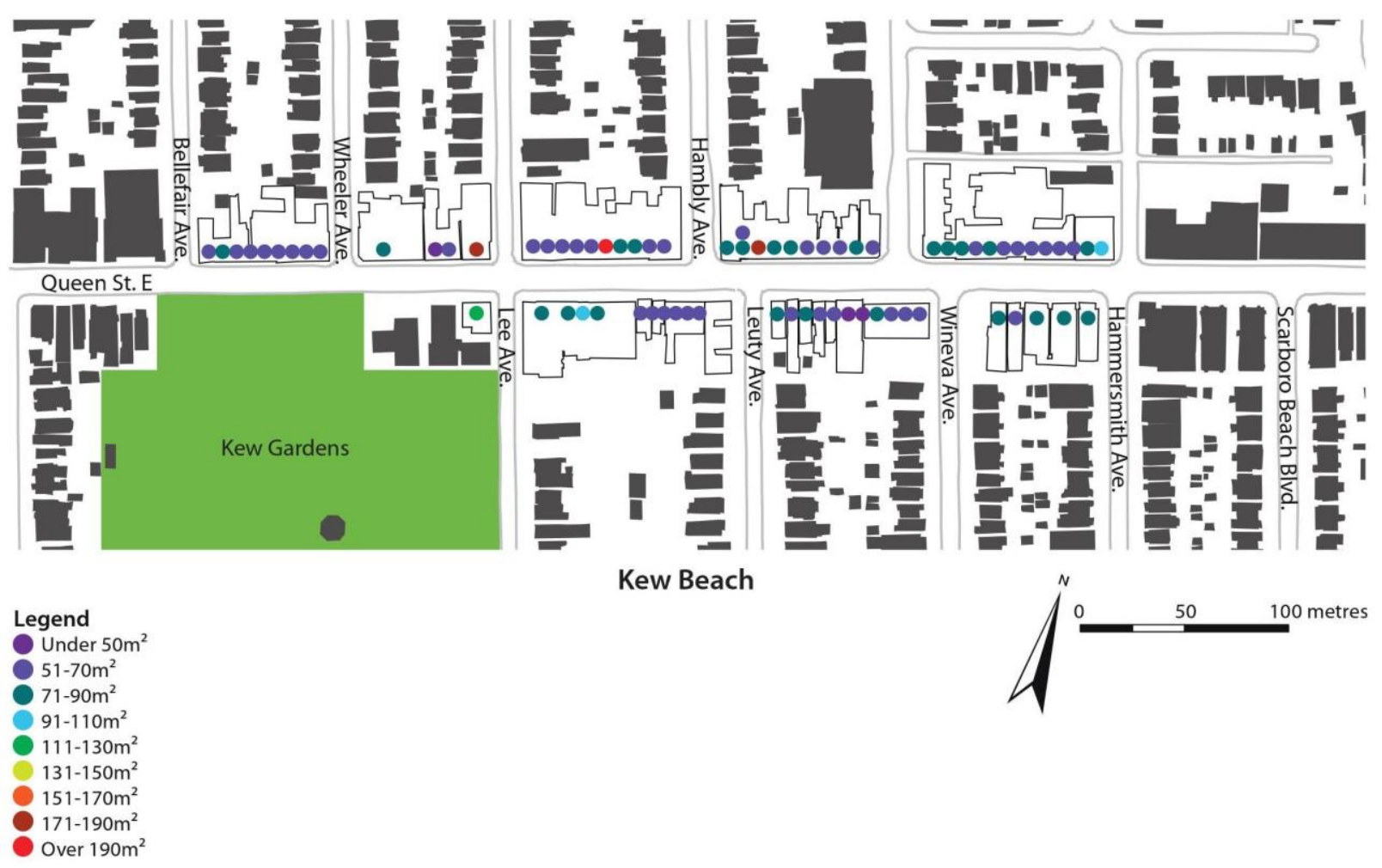

Kew Beach

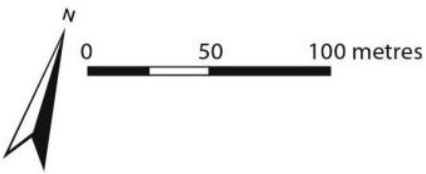

Figure 6: Spatial Distribution of Retail Unit Sizes, 2015

Data Source: CSCA, 2015. 
Figure 6 provides a spatial representation of the retail sizes available in the two study areas. With the exception of the mid-rise building on the northeast side of Brockmount and Queen, the retail sizes in Woodbine Beach are generally random. In contrast, similar retail sizes are often clustered together in Kew Beach. This is quite interesting because Kew Beach has developed incrementally and organically, thus lending itself to more diversity in retail size, lot width and depth, layout and other amenities (e.g. patios, loading areas, parking, garbage storage, mechanical and ventilation functions).

Indicator Summary: Retail size plays an important role in the types of retail tenants and uses within a commercial strip. Low diversity in retail size may restrict the entry of certain businesses and prevent existing businesses from growing or shrinking. Overall, the new mid-rise development in Woodbine Beach supports a larger range of retail size options than the fine grain retail found in Kew Beach. Since the representation of retail size should reflect the local context, in their respective contexts the retail size trends within the two study areas may be appropriate.

\section{PROPORTION OF VACANT PROPERTIES}

In lieu of rent and sales data, the proportion of vacant properties to occupied properties is one of the most effective ways to evaluate the overall health of a particular commercial strip. There are many nuances as to why a retail unit may be vacant, including the unit's price, size, age, visibility, layout, key amenities, condition and ownership structure. On the other hand, external factors like market conditions, customer demand, local competition and accessibility (e.g. pedestrian, cycling, transit and automobile facilities) can influence the amount of vacancy at the neighbourhood level. While it is difficult to evaluate the degree to which each factor affects neighbourhood vacancy rates, the rate itself and the distribution of vacant properties can reveal important differences between retail success in the two study areas.

At first glance the Woodbine Beach study area, characterized by relatively new mid-rise development, appears to be experiencing higher vacancy rates than the traditional fine grain retail in Kew Beach. While there is often a perceived lag time between the completion of a building and the securing of retail tenants in mixed-use development (Baker, 2009), most buildings on the south side of Queen Street in Woodbine Beach were built more than 10 years ago. This suggests that the vacancy rate in this part of the commercial strip should have had enough time to stabilize over the last decade; nevertheless a significant number of vacant units in the area remain. ${ }^{16}$

The Beach also experiences a fair amount of retail turnover. Between 2011 and 2015, 28 percent and 36 percent of retail units experienced a change in tenant in Woodbine Beach and Kew Beach,

\footnotetext{
${ }^{16} 9$ of 23 retail units in March 2016.
} 
respectively (See Appendix 1). In fact, one of the retail units in Woodbine Beach changed retail tenants five times within a five year period. As such, it is important to consider the temporal aspect of vacancy rates in order to get a more complete picture of vacancy trends within the two study areas. The vacancy rates over the last five years are presented in Figure 7.

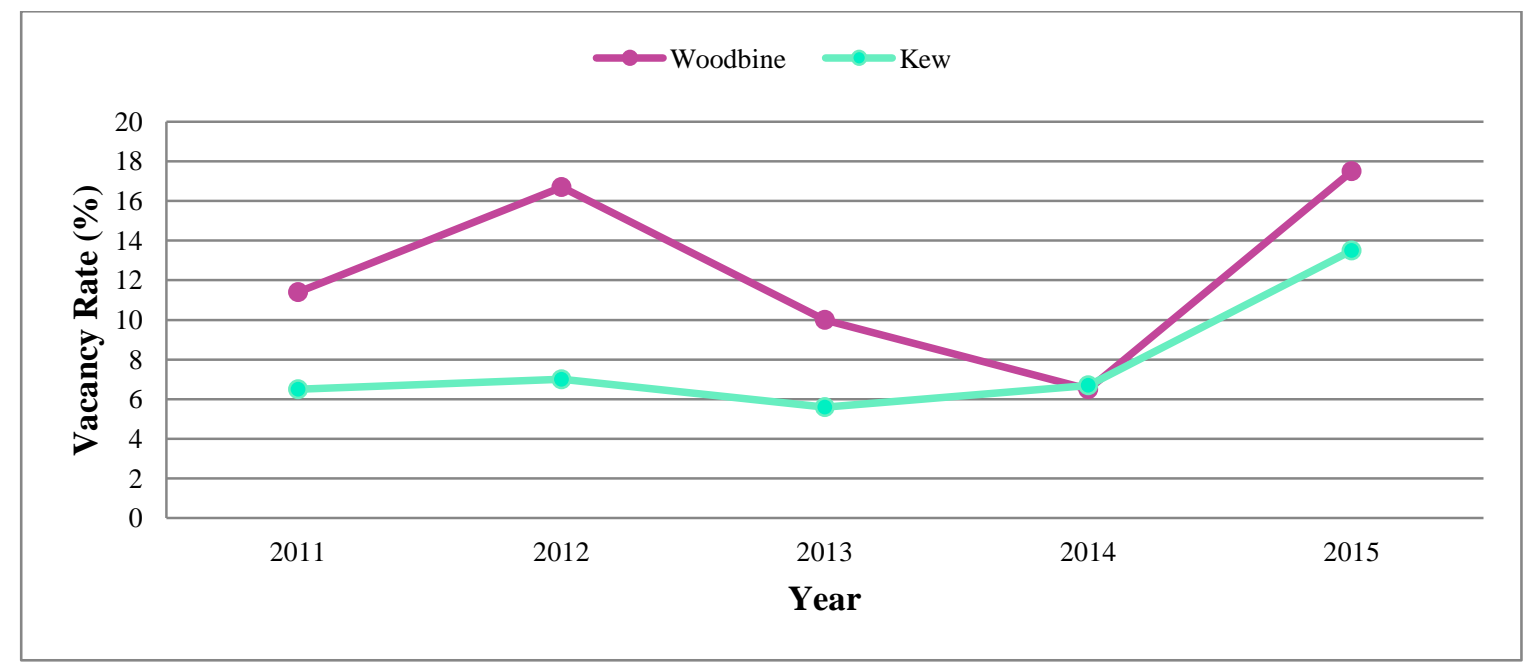

Figure 7: Vacancy Rate between 2011 and 2015

Note: Based on "store" vacancy, as opposed to "space" vacancy

Data Source: CSCA, 2015.

As the figure above shows, Kew Beach's vacancy rate has consistently been lower than in the other study area. The five-year vacancy average of Kew Beach and Woodbine Beach are 7.9 percent and 12.4 percent, respectively; this 6.5 percent difference suggests that there is a higher demand for retail properties in Kew Beach. It can also be observed that Woodbine Beach's vacancy rate rose significantly in 2012 and 2015. The TOcore Retail and Service Study states that this kind of vacancy fluctuation is common in areas that have "poor community building and placemaking," which makes them more susceptible to market changes and other external factors (J.C. Williams Group, 2015, p. 69).

A report published in 2015 by the Centre for the Study of Commercial Activity measured the vacancy rates of 48 commercial strips within the City of Toronto. It found that the average vacancy rate for retail on arterial roads was 9.5 percent in 2014 (Yeates, Hernandez and Murray, 2015). As Figure 7 shows, the vacancy rate over the last five years in Kew Beach was generally 3 percent lower than the city's commercial strip average. In contrast, Woodbine Beach had a more sporadic vacancy rate, where it only dipped below 9.5 percent in 2014. Likewise, Kew Beach also had a relatively good year in 2014; however 2015 brought with it a major spike in the vacancy rates of both study areas. While the underlying factors for this change will not be explored in this study, further examination of this finding may be warranted. 
Another important consideration raised by Katyoka and Wyatt (2008) is the nature of vacancy within a commercial area. They argue that different kinds of vacancy should not yield the same policy implications and interventions. In their research, Katyoka and Wyatt (2008) distinguish between properties that are transactionally vacant (frequent turnover) and structurally vacant (vacancy on a longterm basis). Direct interventions can potentially be used to target clusters of high structural vacancy; this may include working with property owners to make the space more functional for retail tenants or opting for the complete redevelopment of the area.

Persistent vacancy rate, the proportion of properties that are vacant for three or more consecutive years, is a useful measure for determining which areas are experiencing long-term vacancy. When reviewing vacancies over the five-year period between 2011 and 2015, Woodbine Beach and Kew Beach have a persistent vacancy rate of 5 percent and 2.7 percent, respectively. This finding means that longterm vacancy is almost twice as prominent in Woodbine Beach, suggesting the need for a further analysis of the underlying factors contributing to this potentially significant difference.

Interviews with key stakeholders revealed two underlying factors believed to contribute to the high vacancy rate in Woodbine Beach. Firstly, the retail units between Northern Dancer Boulevard and Lockwood Road are less marketable because only the south side of the street features retail uses. Toronto's Avenue and Mid-rise Buildings Study states that "double-loaded retail" corridors facilitate retail competition and generate more retail vibrancy than corridors which only have retail on one side of the street (Brook McIlroy Planning and Urban Design/Pace Architects, 2010 b).

Two interviewees stated that another factor contributing to vacancy is Ontario's property tax rebate program for vacant commercial and industrial buildings. This program allows commercial property owners to apply for a 30 percent rebate if their property, or part of their property, has been vacant for 90 or more consecutive days (City of Toronto, n.d. b). This program creates a disincentive for property owners to actively seek new retail tenants. The City of Toronto has recently become interested in redesigning the program in order to foster economic growth and job creation. It is looking at new ways to support temporary uses on vacant properties; these uses include incubator and accelerator programs, as well as pop-up businesses and cultural activities (City of Toronto, 2014).

Community and private sector initiatives have also been used to decrease commercial vacancy rates. Pop-ups have been quite successful in certain neighbourhoods due to the involvement of resident and community groups (e.g. Danforth East Community Association's Pop-up Shop Project). A representative from the Beach Village BIA commented that while pop-ups are welcome in the Beach neighbourhood, the uptake has been limited to only a few proactive commercial property owners. 
Indicator Summary: The vacancy trends in the Beach neighbourhood confirm that retail performance is diverging in the two study areas. With a higher and fluctuating vacancy rate, Woodbine Beach is particularly vulnerable to external market conditions. Nevertheless, new thinking around temporary uses within the neighbourhood, and the city as a whole, may have some interesting implications for the future of vacant properties in the Beach neighbourhood.

\section{RETAIL RENTS}

The cost of retail rent is a determining factor in the type of commercial tenants and retail uses that are feasible for a particular property. While commercial rental rates are generally based on market rates of comparable properties, the terms and conditions of the leasing agreement are negotiated between the property owner and the tenant. Although rental increases and escalation rates are usually negotiated as part of the leasing agreement, the property owner may increase the rent at their discretion once the lease expires (Legal Line, n.d.). ${ }^{17}$

Since the terms of commercial leases are negotiated, independent businesses may find themselves in a weaker bargaining position and may not be fully aware of what terms and conditions are reasonable for leasing contracts. Moreover, high retail rents are a barrier to entry for many smaller businesses that need time and capital to establish their business, and generate enough sales to offset the cost of the rent. Conversely some property owners may be willing to negotiate more flexible leases, with a shorter term or on a "percentage of sales" basis (Mirel, 2010). This approach has primarily been used during market downturns or for persistently vacant properties.

Ownership structure could also have an indirect impact on retail rent. When mid and high-rise developers retain ownership of the commercial space in their projects, their high overhead costs make it preferable to find large established tenants, who are financially stable and able to uphold a long-term lease (Dalglish, 2014; Schabas, 2012). The need to offset municipal approval and construction costs is incorporated into the asking price of both commercial and residential space further hindering the likelihood of small independent businesses locating in mid and high-rise buildings.

Although the actual ratio of owned versus leased retail units in the Beach neighbourhood is unknown, interviews with tenants and real estate agents suggest that most food services and retail merchandise stores are leased. The average cost of commercial space was also not explored in this study; nevertheless, interviews revealed that rents are highly sensitive to location within the commercial strip. The rent of a commercial property is dependent on the quality of existing public infrastructure (e.g. major

\footnotetext{
${ }^{17}$ Unless there is a pre-set amount negotiated in the original lease.
} 
roads and transit), type of surrounding land uses (e.g. park and institutional uses) and proximity of successful commercial tenants (e.g. coffee shops). Therefore, the rent of a prime location may be double that of another retail unit within the commercial strip.

Commercial rent affordability was a common theme in the interviews. Some interviewees felt that current retail rents are not sustainable, pushing certain retail tenants out of the neighbourhood. They also suggested that property owners are generally disconnected from their tenants, the community and the Beach Village BIA. In fact, little is known about the property owners apart from the information that is collected by the Municipal Property Assessment Corporation (MPAC), which includes their Ontarioregistered name and mailing address.

Indicator Summary: While little can be concluded regarding the retail rent affordability in the Beach neighbourhood, there is evidence to suggest that average rents have been rising significantly. This trend may be linked to any number of things, including city-wide market conditions, rise in cost of living, new infill development in the neighbourhood etc. More research will be required to determine the true underlying factors of this trend.

\section{RETAIL REPRESENTATION AND NEW POLICY DIRECTIONS}

Retail representation speaks to the current and future retail trends within a commercial strip. Changes in these representations may reveal emerging opportunities for retail tenants and real estate developers. These changes can be market driven, based on consumer preferences and market conditions, or policy driven, through the use of official plans, by-laws and urban design guidelines.

Literature on retail vibrancy often argues that traditional main streets should primarily serve retail functions and support local independent businesses (Grant and Perrott, 2011; Alexander and Shaw, 2012). As opposed to services, retail functions (including retail merchandise, and food and drug retail), generate more foot traffic, and encourage casual browsing and window shopping behaviours. While this may be true, between the 1960s and 2014 the ratio of retail uses to non-retail uses has shifted from 60:40 to 38:62 in the City of Toronto. This shift has been dominated by an explosive growth in food services and personal services over the last five decades (Yeates, Hernandez and Murray, 2015). The literature also posits that local independent businesses should be preferred to larger retail chains because they support the local economy through local job creation and reinvesting of profits back into the community. These local businesses usually play an important role in community building through greater community involvement and create a sense of place by reinforcing the unique character of main streets (Alexander 
and Shaw, 2011). However, mixed-use infill development in the city has helped major retailers find suitable commercial space on highly lucrative main streets.

Planning literature also suggests that while the ideologies behind mixed-use development are admirable, mixed-use development facilitates the growth of service uses and big chain retailers in main street areas (Grant and Perrott, 2011). In fact, big retailers have begun rethinking their store formats (e.g. vertical stores) and business models (e.g. streamlined inventory) to remain viable in urban markets (Murray and Hernandez, 2015). This shift in thinking has been a contributing factor to the gradual decrease of store sizes since the recession of 2008 (J.C. Williams Group, 2014).

Table 4: Representation of Retail Types, 2015

\begin{tabular}{|lrrrr|} 
& Woodbine Beach & \multicolumn{2}{c|}{ Kew Beach } \\
\hline & $\#$ & $\%$ & $\#$ & $\%$ \\
\hline Retail Merchandise & 9 & $32.8 \%$ & 21 & $27.3 \%$ \\
\hline Food/Drug Retail & 3 & $7.8 \%$ & 5 & $9.1 \%$ \\
\hline Food Services & 6 & $28.1 \%$ & 18 & $18.2 \%$ \\
\hline Other Services & 14 & $31.3 \%$ & 20 & $42.4 \%$ \\
\hline Total* & $\mathbf{3 3}$ & & $\mathbf{6 4}$ & \\
\hline
\end{tabular}

*Not including vacant retail units

Data Source: CSCA, 2015.

Table 4 shows that the ratios of retail merchandise uses to other service uses in Woodbine Beach and Kew Beach are 1:1 and 3:4, respectively. Based on the assumption made in the literature, Woodbine Beach should be the more attractive shopping destination, as it has a large amount of specialty retail stores, selling furniture, lighting, art supplies and motorcycle merchandise. In practice however, this type of retail is more likely to attract destination shoppers who have clear shopping intentions, which do not necessarily involve casual browsing in other stores.

At the neighbourhood level, the commercial representation of retail merchandise and other services along Queen Street is relatively similar in the Beach, Leslieville and Riverside neighbourhoods. Retail trade accounts from 31 to 34 percent of the retail mix, while service uses range from 19 to 21 percent. While the Beach has a slightly higher proportion of education services, the other two neighbourhoods have more professional, science and technology services (Darkwah, 2015, a, b \& c). This may point to the demographic differences in the neighbourhoods, as the Beach has a larger proportion of young families with kids while the other two neighbourhoods have a more dominate population of young professionals.

Table 5 summarizes the types of commercial tenants in the Beach Neighbourhood based on their market size. Although, Kew Beach has proportionally more local and regional commercial tenants, the 
two study areas seem to be on par in multinational commercial tenants. The dominance of local commercial tenants in Kew Beach is to be expected as its fine grain and pedestrian orientation is conducive to smaller-scale businesses.

Table 5: Proportion of Commercial Tenants by Market Size, 2015

\begin{tabular}{|lrrrr|} 
& Woodbine Beach & \multicolumn{2}{c|}{ Kew Beach } \\
\hline & $\#$ & $\%$ & $\#$ & $\%$ \\
\hline Local (Single location in the Beach) & 15 & $45 \%$ & 33 & $52 \%$ \\
\hline Regional (in the GTA) & 4 & $12 \%$ & 9 & $14 \%$ \\
\hline Province wide (in Ontario) & 4 & $12 \%$ & 5 & $8 \%$ \\
\hline Nationwide (in Canada) & 4 & $12 \%$ & 6 & $9 \%$ \\
\hline Multinational & 6 & $18 \%$ & 11 & $17 \%$ \\
\hline Total* & $\mathbf{3 3}$ & & $\mathbf{6 4}$ & \\
\hline
\end{tabular}

*Not including vacant retail units

Data Source: CSCA, 2015.

Although it is widely believed that retail gentrification replaces "mom and pop" businesses with large big box commercial tenants, not all retail literature has supported this finding. Crosby et al (2005) find that local commercial tenants are in direct competition with smaller chains for prime main street real estate. In fact, the DC Vibrant Retail Street Toolkit (2012) suggests that local and national commercial tenants are equally important to main streets. Based on this assumption the two study areas have a healthy retail representation.

Another important consideration in current and future retail representation is market supply. Since the encouragement of mixed use brings with it an expectation of additional retail uses at grade, some have argued that this may contribute to the oversupply of retail space in neighbourhoods that do not have an adequate customer base to sustain the stock (Grant and Perrott, 2011). Several interviewees have observed that the Beach experiences a low amount of through traffic and primarily relies on local residents as its core customer base. Consequently, continued retail development may result in the outpacing of local market demand. The oversupply of retail could potentially contribute to a higher vacancy, while having no noticeable impacts on retail representation. Moreover rising housing prices across the city have affected discretionary spending habits (J.C. Williams Group, 2014); this may have further implications on the carrying capacity of the neighbourhood with regards to retail quantity and size.

While it is not possible to systematically predict how the retail representation might change in the future, the character of the Beach neighbourhood makes it possible to make certain assumptions. Key shareholders familiar with the neighbourhood's history have suggested that "trendy" restaurants are fairly common in the Beach. Waves of culinary trends have come and gone; these have most recently included 
burger restaurants, yogurt shops and burrito places just to name a few. In fact, the Beach urban design guidelines encourage restaurants and cafés in new developments, stating that new commercial space should be able to accommodate full-service restaurants (City of Toronto, $2012 \mathrm{~b}$ ).

There are also a few other planning policy tools which have the potential to influence the future retail representation in the neighbourhood. The first is a new Queen Street East restaurant study, ${ }^{18}$ which, once completed, will replace the policies under the Queen Street East Licenced Eating Establishment Study (1985). ${ }^{19}$ The purpose of the new study is to improve the economic health of restaurants while preserving the character of Queen Street and mitigating any impacts on community residents. In March 2016, a community meeting was held to inform the public about this study and the existing policies regarding restaurant size restrictions, parking requirements and permitted accessory uses (Pantazis, 2016). Any policy changes resulting from the study, be them more or less permissive, will have an impact on the type and quantity of restaurants in Kew Beach.

Another important planning tool is the zoning by-law amendment, which is required for most new developments in the city. By-laws further refine the site-specific requirements regarding the form, height and density of different uses, as well as the types of building materials used. For example, a new development at 1960-62 Queen Street East (the site of the former Lick's restaurant) must accommodate two retail tenants, each with a maximum floor area of 325 square metres, unless the tenant is a bank or financial institution (City of Toronto, 2012 c). Unfortunately, this requirement is not very stringent, since most of the retail units in the neighbourhood are well below this size. All the same, zoning by-law amendments could play an important role in interim retail planning, until a more centralized retail planning approach is developed.

Indicator Summary: Kew Beach is dominated by local and regional commercial tenants who generally provide more service uses than retail uses; whereas, Woodbine Beach generally has a more evenly distributed retail representation. Although, the impact of this finding on retail vibrancy is inconclusive, it raises further questions about the validity of main street ideologies regarding the need for more retail uses and "mom and pop" tenants. In addition, the current character of the Beach neighbourhood is heavily influenced by its restaurants and cafés. As such, the Beach urban design guidelines and new restaurant study will play an important role in shaping a major part of the retail offerings in the area.

\footnotetext{
${ }^{18}$ Study boundaries are Woodbine Avenue to Victoria Park Avenue; thus, it only encompasses Kew Beach and Balmy Beach.

${ }^{19}$ Enacted to "mitigate impacts such as noise, litter, traffic congestion, and disruptive behaviour" associated with restaurants.
} 


\section{PUBLIC REALM AND ENVIRONMENTAL QUALITY}

The public realm and its environmental quality are integral components in preserving the main street character of Queen Street East. A well-designed pedestrian-oriented public realm attracts high volumes of visitors and facilitates the creation of a sense of place (Streetsense, 2012). High environmental quality speaks to the overall cleanliness and maintenance of the public realm. Achieving a public realm with high environmental quality attracts visitors all year round and creates opportunities for people to linger, browse and window shop.

Streetscape elements, such as hard and soft landscaping, street furniture, signage and weather protection, are very important to the public realm. To be effective, these elements should be consistent, uncluttered, durable and well-maintained. Consistent signage (Picture 1) and animated landscaping (Picture 2) are apparent throughout the Beach neighbourhood. In the summer, streets are lined with trees, flowers and other plants, reinforcing the neighbourhood's branding as a beach resort town. Similarly the environmental quality of the area is quite high; the presence of community murals (Picture 3 ) and the absence of garbage, graffiti and other vandalism contribute to the overall aesthetic of the Beach.

The responsibility of the public realm, and its quality, is usually shared between retail tenants, retail property owners, business improvement areas and several City departments. As a result, these stakeholders need to work together to maximize the potential of the public realm, which in turn supports

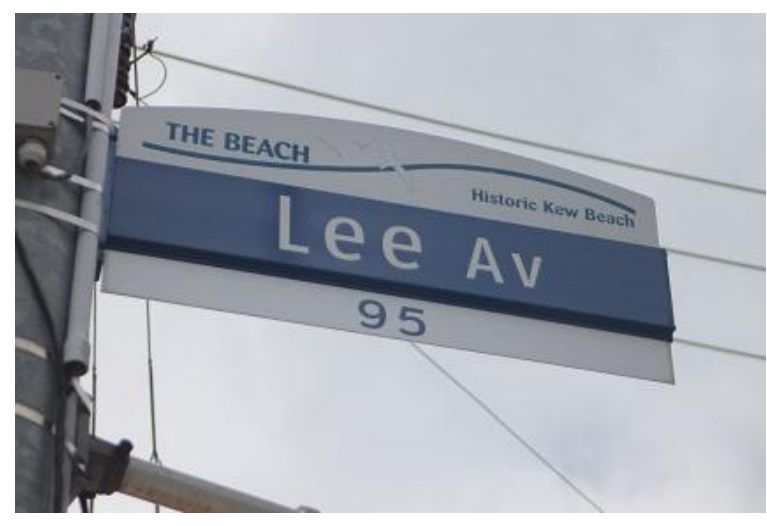

Picture 1: Precinct-specific signage

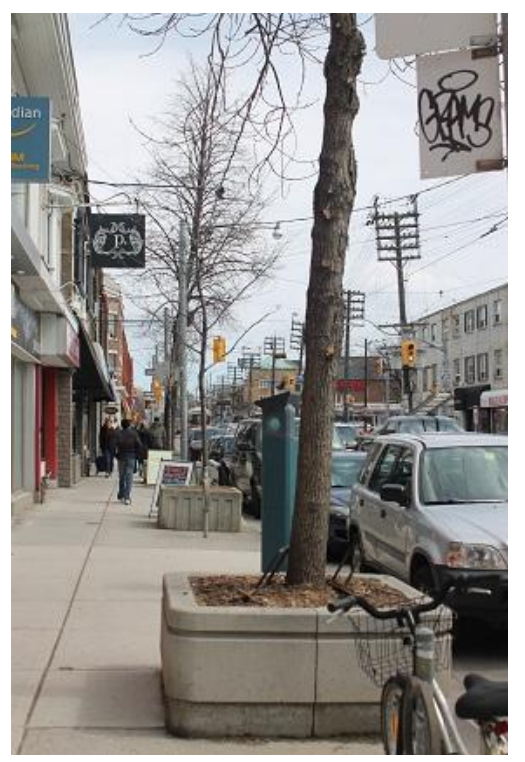

Picture 2: Tree planters (generally along the north side of the street)

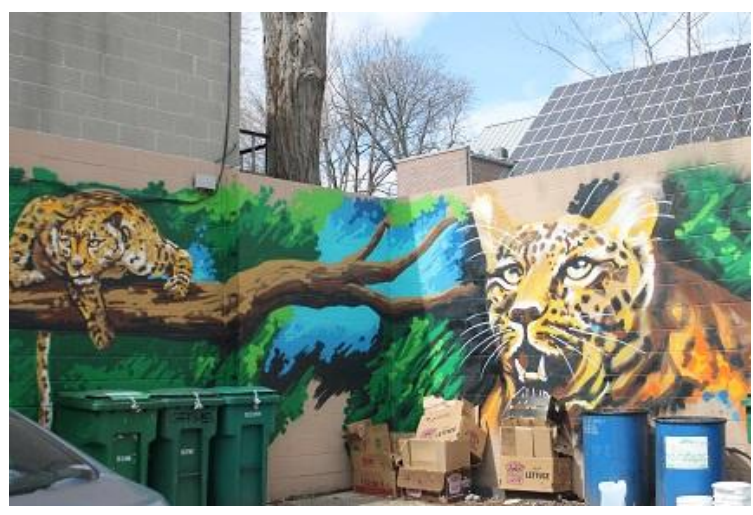

Picture 3: Mural on Wineva and Queen 
retail vibrancy. Most landscaping, garbage collection, and general street maintenance are handled by the City, while special streetscape beautification and promotional events (e.g. Jazz Fest and Family Day Event) are spearheaded by the Beach Village BIA. Storefront animation is usually in the domain of retail tenants, but leasing agreements might have specific terms and conditions regarding what type of animation and improvements are handled by the property owner and the retail tenant, respectively.

One of the challenges with public realm improvement on traditional main streets is that narrow sidewalk widths make it challenging to incorporate street furniture and landscaping without cluttering the street. Narrow sidewalk widths also impede the City's ability to permit certain uses like outdoor cafés, for restaurants which do not have the proper setbacks to have a patio within their property lines. Outdoor cafés have the potential to play an important role in building a sense of place, while expanding the physical capacity of businesses to accommodate more customers. If Toronto's winter climate is addressed in their design (e.g. weather protection features like awnings and heat lamps), outdoor cafés can also contribute to all year round retail vitality.

Since Kew Beach has a relatively narrow sidewalk width, streetscape features and outdoor cafés are less feasible. Nevertheless, the generous sidewalk widths and front setbacks of some of the mid-rise buildings in Woodbine Beach provide opportunities to improve the public realm (Picture 4). The Beach urban design guidelines regarding generous sidewalk widths will also facilitate opportunities for streetscape improvements in new developments. Moreover, innovative design approaches, like the temporary

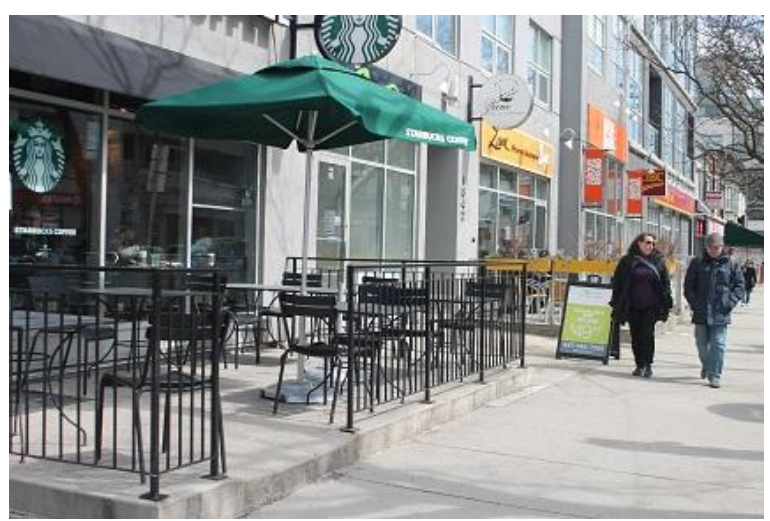

Picture 4: Generous sidewalk for mid-rise at the northeast corner of Brookmount and Queen conversion of parking spaces into streetside parklets (i.e. Church Street and John Street) and vending stalls can also be introduced in areas where redevelopment is unlikely.

Another barrier to improvement of the public realm is the design and form of existing buildings. The design of buildings, specifically their façade and height, can impede effective storefront animation. Indeed, the Beach urban design guidelines call for continuous streetwalls and discourage arcades, colonnades and internal malls; these policy directions have emerged as a result of lessons learned from the existing build form in the neighbourhood. 
The south side of Queen Street in Woodbine Beach features arcades; the poor visibility and lighting which result from this architectural style makes it difficult to animate storefronts. As a result, some of the businesses in this study area have not been actively seeking opportunities to animate their windows, opting for the use of blinds and curtains (Picture 5). On the other hand, Kew Beach is populated with a variety of animated storefronts which have been essential to enhancing the character of the commercial strip (Picture 6).

Although design guidelines can improve storefront animation in new development, novel ideas will be needed to establish more active and inviting retail displays in buildings which are less than ideal from a retail vitality perspective. This might involve displaying merchandise outside or having outdoor signage and information boards listing specials and featured items.

Another important component to the public realm, and its environmental quality, are community anchors like public facilities, educational institutions, religious institutions, and parks and open space. Since these anchors attract a significant amount of local residents on a daily basis, businesses nearby may benefit from the additional foot and vehicle traffic generated in the neighbourhood. This is especially true for convenience retail and services, like grocery stores, convenience stores, dry cleaners etc.

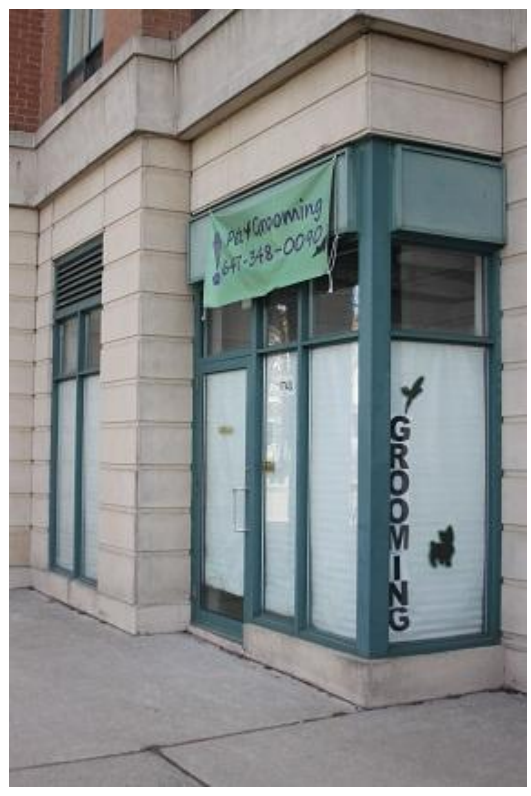

Picture 5: Pet groomers with temporary paper blinds

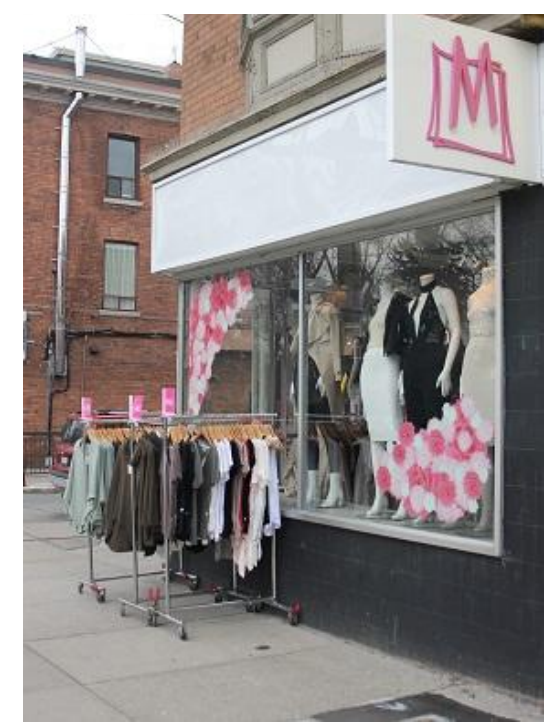

Picture 6: Animated storefront with spill out activities 


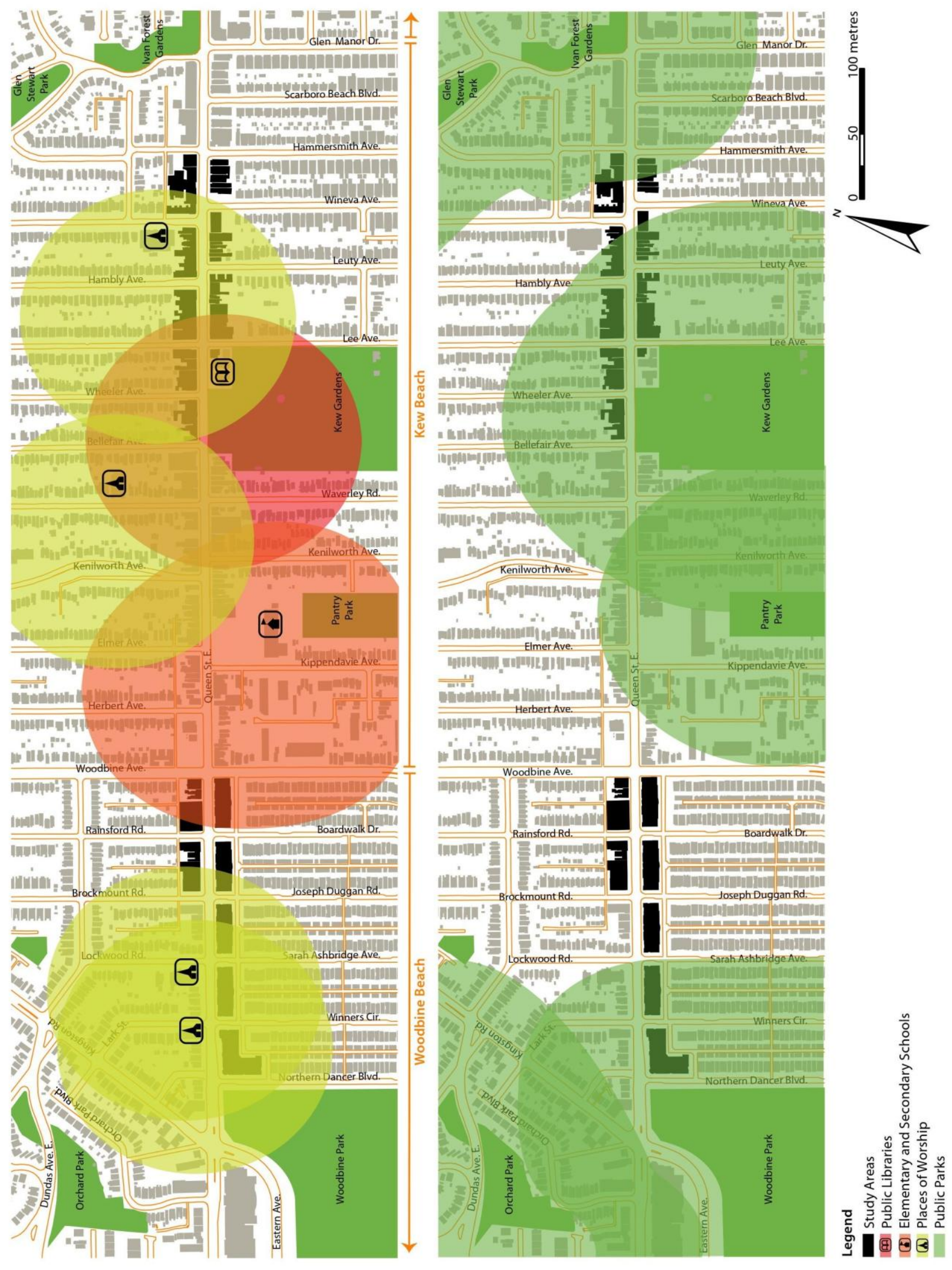

Figure 8: Semi-private and Public Facilities near the Study Areas

Note: Based on 100 metre buffer

Data Source: City of Toronto, n.d. b 
Figure 8 displays the various community anchors in the two study areas, with a 100 metre buffer. These anchors appear to be more evenly dispersed in Kew Beach, suggesting that its convenience retail may benefit from multiple sources of local foot and vehicle traffic. However, a more thorough analysis using surveys or traffic counts will be necessary to test this assumption.

Indicator Summary: A high quality public realm can facilitate retail vibrancy. Kew Beach and Woodbine Beach both have their public realm challenges; the latter with regards to its built form and the former with regards to its narrower right-of-way width. New and innovative ideas to animate streets and storefronts will be needed to strengthen the character of the whole commercial strip and provide a seamless transition between the three precincts. Nevertheless, tracing the cause-and-effect relationship between an intervention and the resulting improvement in retail vibrancy is quite challenging.

\section{ACCESSIBILITY}

Accessibility to and within a commercial strip plays a central role in attracting visitors. It determines how many people are coming, where people are coming from, and how they are getting there (DECG, 2012). In Toronto, retail trends have consistently shown that one of the key underlying factors affecting people's choices regarding where and how they travel is overall convenience (J.C. Williams Group, 2014).

While the most common forms of travel are walking, cycling, transit and driving, street design must make tradeoffs between these four modes of travel. Traditional main streets usually prioritize walking, since their narrow widths often impede the installation of bike and transit infrastructure, as well as lane widening for vehicles. Newer main streets are wider to accommodate vehicular traffic, higherorder transit and bike lanes. This means that these streets are often less pedestrian-oriented, relying on a customer base from a broader geographic area.

Another important consideration is how the layout of the retail impacts the way visitors get there. In Toronto, older arterial roads are dominated by three retail layout forms: main street, strip mall and plaza. Like main streets, strip malls feature adjoining retail units parallel to the street; however, public parking spaces are usually located within the property line between the retail units and the right-of-way. Plazas are usually larger, particularly in lot depth; they feature bigger retail units and significantly more parking space (Linovski, 2012). Plazas also normally abut multiple right-of-ways and are designed to have multiple access points from both major and side streets. While all three retail forms specialize in convenience retail offerings, strip malls and plazas are significantly more vehicle-oriented, thus capturing a wider catchment area. 


\begin{tabular}{|c|c|c|c|}
\hline & Woodbine Beach & Kew Beach & Balmy Beach \\
\hline $\begin{array}{l}\text { Walk } \\
\text { Score }\end{array}$ & $\begin{array}{l}89 \text { - Very Walkable } \\
\text { (Most errands can be } \\
\text { accomplished on foot) }\end{array}$ & $\begin{array}{l}93 \text { - Walker's Paradise } \\
\text { (Daily errands do not require } \\
\text { a car) }\end{array}$ & $\begin{array}{l}90 \text { - Walker's Paradise } \\
\text { (Daily errands do not require } \\
\text { a car) }\end{array}$ \\
\hline $\begin{array}{l}\text { Transit } \\
\text { Score }\end{array}$ & $\begin{array}{l}83-\text { Excellent Transit } \\
\text { (Transit is convenient for } \\
\text { most trips) }\end{array}$ & $\begin{array}{l}78-\text { Excellent Transit } \\
\text { (Transit is convenient for } \\
\text { most trips) }\end{array}$ & $\begin{array}{l}78-\text { Excellent Transit } \\
\text { (Transit is convenient for } \\
\text { most trips) }\end{array}$ \\
\hline $\begin{array}{l}\text { Bike } \\
\text { Score }\end{array}$ & $\begin{array}{l}90-\text { Biker's Paradise } \\
\text { (Flat as a pancake, excellent } \\
\text { bike lanes) }\end{array}$ & $\begin{array}{l}89-\text { Very Bikeable } \\
\text { (Mostly flat, excellent bike } \\
\text { lanes) }\end{array}$ & $\begin{array}{l}63-\text { Bikeable } \\
\text { (Some hills, some bike } \\
\text { lanes) }\end{array}$ \\
\hline
\end{tabular}

Data Source: Walkscore.com

When looking at the Walk, Bike and Transit score for the three precincts in the Beach neighbourhood (Table 6), Kew and Balmy Beach perform marginally better in Walkscore, while Woodbine Beach has better bike and transit facilities. Since the south part of Woodbine Beach was built in the 2000s, expropriation for road widening made it possible to have wider lanes along Queen Street. On the other hand, Kew and Balmy Beach are much older areas, where the existing built form remains pedestrian-oriented at the expense of transit and vehicle traffic.

Pedestrian, bike, transit and vehicle access are mapped in Figure 9. Although the 501 Queen Street streetcar services both study areas, Woodbine Beach has slightly better north-south connections (based on frequency and number of routes) to the Bloor subway line. Similarly, it also has more formalized biking infrastructure in the form of bike lane and multiuse paths. In contrast, the figure shows that there a more traffic lights and one-way roads in Kew Beach which slows down and restricts traffic in favour of pedestrian safety.

Interviews with stakeholders found that one of the biggest challenges to accessibility in the Beach neighbourhood is the availability of parking. The neighbourhood offers a very limited amount of on-street parking spaces, which are even more constrained during morning and evening rush hour when parking or idling on Queen Street is prohibited. Winter maintenance protocols and summer tourism also put additional pressure on parking availability in the neighbourhood. It appears that the two study areas are not impacted by this problem to the same degree. Field observations of Kew Beach have confirmed that parking is a significant challenge, especially during weekends and evenings, as well as on special event days. In contrast, Woodbine Beach seems to not have the same parking demand; on-street parking, and parking at the rear of the buildings on the south side of Queen Street are usually not at capacity. 

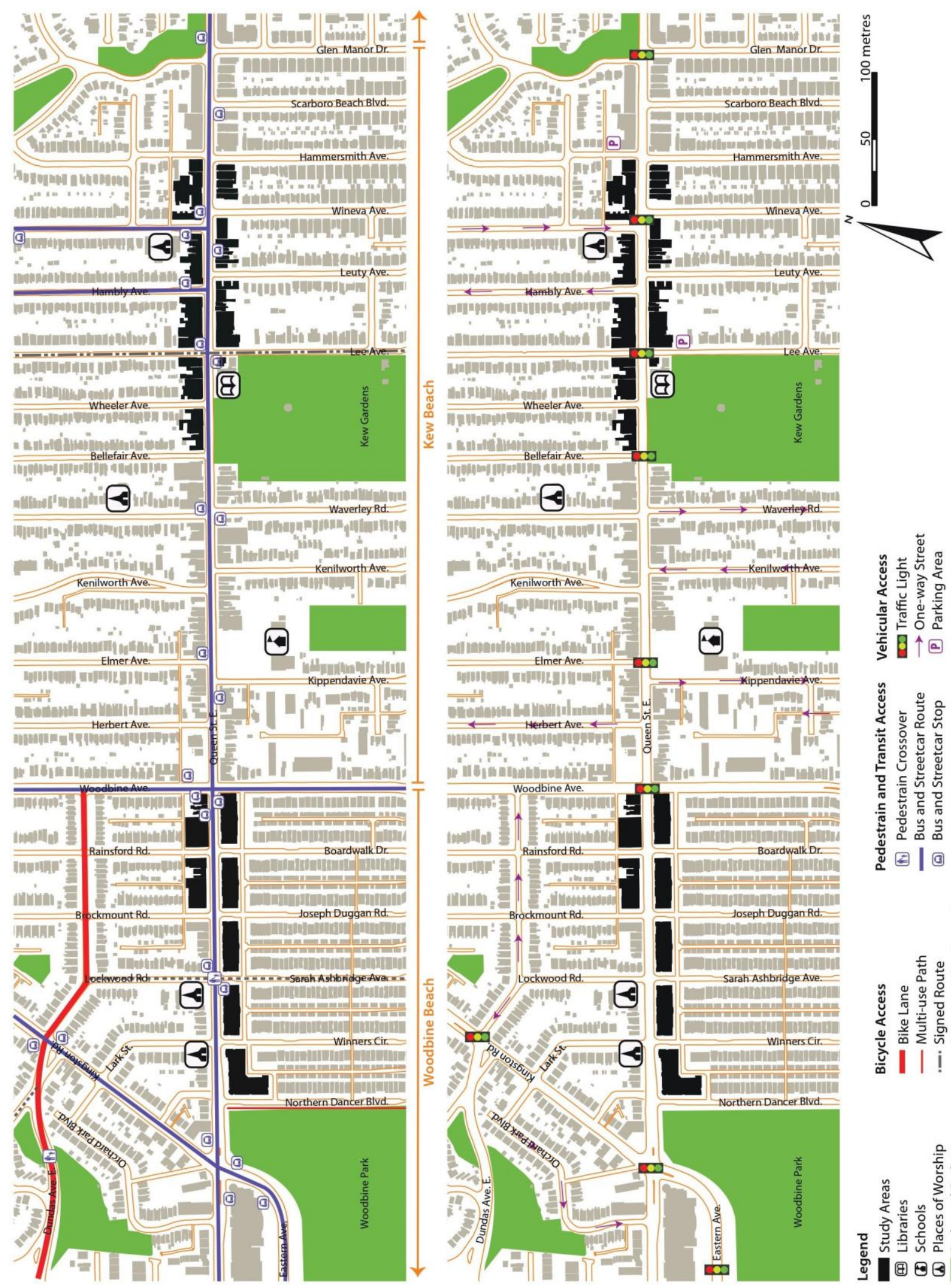

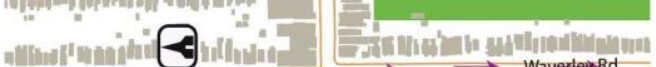

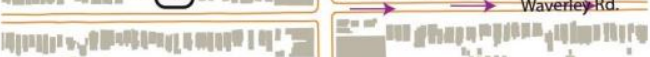

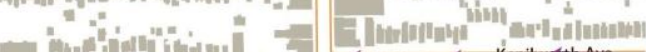

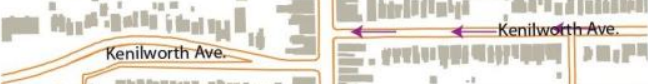

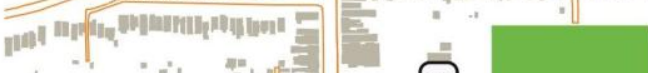

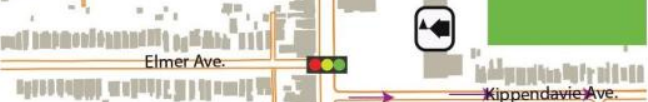

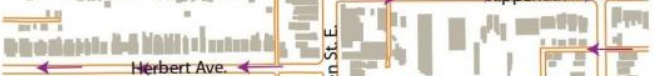

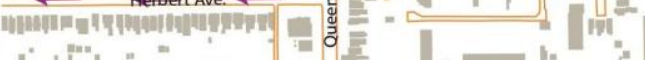

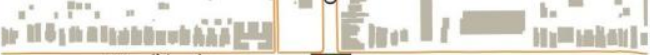

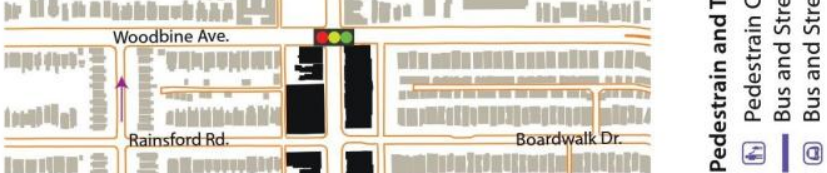

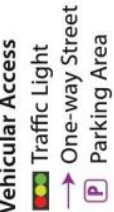

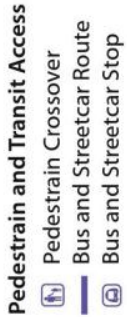

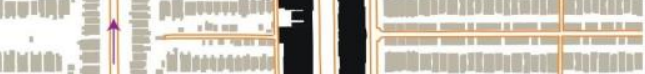

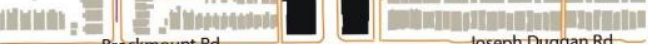

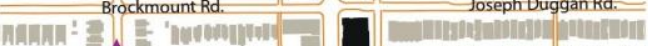

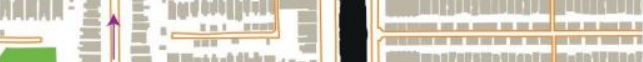
ए

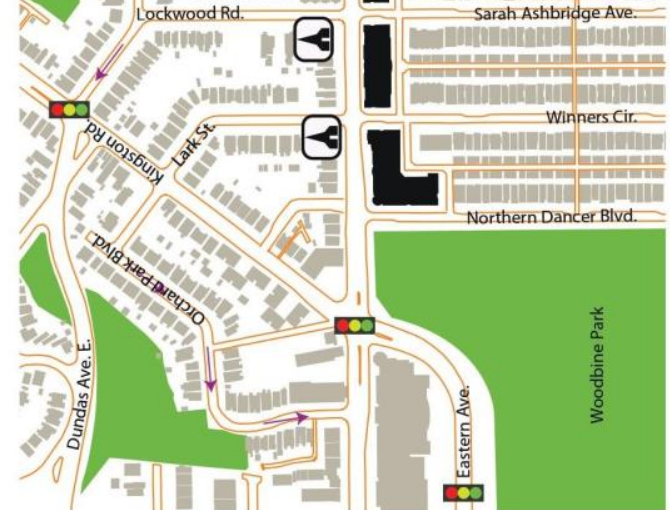

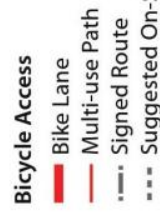

Figure 9: Accessibility to the Study Areas Data Source: City of Toronto, n.d. b. 
While the City has acknowledged that parking is a problem in the neighbourhood, there are nearly no suitable parcels of land in the neighbourhood which can serve as a parking lot. Although new mid-rise development could potentially provide underground parking to add new parking spaces to the neighbourhood, there are a variety of geological constraints which makes below grade parking impractical (e.g. high water table and poor soil quality).

Indicator Summary: The way in which visitors access a commercial strip has a profound impact on the type of retail which is needed. While there is no one single formula to achieving retail vibrancy, the retail mix should reflect the strengths of the public infrastructure in the neighbourhood. As such, Kew Beach should focus on its pedestrian customer base, while Woodbine Beach should continue servicing customers using transit and vehicles. Nevertheless, when possible, improvement opportunities in pedestrian, cycling, transit and vehicular infrastructure should always be pursued by the City.

\section{CUSTOMER VIEWS \& BEHAVIOUR AND TRAFFIC FLOWS}

At the level of the individual shopper, opinions and views about a commercial strip have an impact on personal shopping behaviour. Surveys on customer satisfaction can help monitor and evaluate the success of commercial strips, which can help city planners, BIAs and businesses make informed decisions regarding future interventions intended to improve retail vibrancy and market performance (DECG, 2012). However, this method of data collection poses several challenges regarding the spatial boundary for the target audience, poor response rates without added incentive, and level of honesty which can be expected from respondents (Neuman and Robson, 2012).

At the aggregate level, pedestrian flows can help explain how these customer views and behaviours manifest themselves in general traffic movement. Traffic counts through field observations can illustrate trends in market demands, movement patterns, and relative popularity of different subsections of a commercial strip. Traffic counts at different times of day, week and year on an ongoing basis can also help demonstrate the relative vibrancy of retail over time.

No comprehensive surveys or traffic counts were undertaken in this study; however, a few assumptions were made based on observations and interview findings. First, pedestrian traffic appears to be denser in Kew Beach than in Woodbine Beach, especially after school and on evenings and weekends. While businesses are usually busiest on evenings and weekends, restaurants and cafés see volume pick up over the lunch hour. Their daytime customer base mainly includes employees of nearby schools and banks, and young parents and nannies. In contrast, vehicle traffic picks up during regular peak hours, as well as throughout the summer months, particularly when community events are being hosted. Bike 
traffic is generally minimal along Queen Street as most cyclists use alternate routes, like the Martin Goodman Trail and Dundas Street East.

Indicator Summary: Customer satisfaction surveys and traffic flows are important sources of information in determining market demands, as well as possible areas for public investment and improvement. While no conclusions can be made based on the findings made regarding the two study areas, there are opportunities for further research and analysis. This type of neighbourhood-level analysis would be a valuable low-cost undertaking for the Beach Village BIA or one of the ten residence associations in the neighbourhood.

\section{SAFETY \& OCCURRENCE OF CRIME}

The occurrence of crime is usually a relative measure which helps explain why people choose to live, work or shop where they do. Scholars argue that crime occurrences can be discouraged by increasing natural surveillance, supporting outdoor activities and programs, controlling access through heighten security, and separating private from public property (Kajalo and Lindblom, 2015). Nevertheless, wellconnected and retail supportive neighbourhoods, which have regular pedestrian flow and sufficient street lighting, can also influence the likelihood and the type of crime committed (Sohn, 2016). Interestingly enough, crime occurrences are highly localized and rooted in place; this means that neighbourhoods with high crime rates are often close to those with low levels of crime (e.g. Moss Park and Cabbagetown). The occurrence of crime has an impact on both the supply and demand of retail; affecting whether a retailer wants to locate in the area, as well as whether shoppers want to shop there.

Table 7: Number of Crime Occurrences by Neighbourhood, 2011

\begin{tabular}{|lrrrrrr|}
\hline & The Beach & & \multicolumn{2}{c}{ South Riverside (West) } & $\begin{array}{c}\text { Birchcliffe \& Cliffside } \\
\text { (East) }\end{array}$ \\
& $\#^{*}$ & Rank** & $\# *$ & Rank** & \#* & Rank** \\
\hline Break and Enter & 119 & 24 & 182 & 5 & 105 & 45 \\
\hline Robbery & 11 & 131 & 47 & 56 & 39 & 62 \\
\hline Theft $(\$ 5000+)$ & 7 & 58 & 9 & 50 & 9 & 37 \\
\hline Assault & 54 & 96 & 108 & 36 & 95 & 45 \\
\hline
\end{tabular}

* Number of occurrences per 10,000 residents in the neighbourhood

** Rank out of 140 Toronto neighbourhoods based on absolute number of occurrences

Data Source: Friesen, D. and Rajagopalan, P, n.d. based on Toronto Police Services data, 2011.

Unfortunately the only crime data available for the study was at the neighbourhood level; therefore, a comparison of crime rates between the two study areas is not possible. Table 7 shows the crime rates in 2011 for the Beach along with the two neighborhoods directly east and west. On a per capita basis, the Beach experiences fewer robberies, thefts (over \$5000) and assaults than the two surrounding neighbourhoods. Breaking and entering occurrences seem to decrease moving east and away 
from the city core, on a per capita basis. At the city-level and in absolute terms, the Beach ranks relatively high in the amount of breaking and enterings, as well as a very low on the number of robberies. These findings suggest that while the personal safety of shoppers is relatively high, businesses are more likely to be victims of a burglary than in other neighbourhoods.

Indicator Summary: While there are a number of factors that can affect the occurrence of crime in a neighborhood, many of them are difficult to control. Improving visibility and street lighting may help make areas safer and more attractive for businesses and shoppers. Ultimately, businesses and shoppers should be aware of the risks in each neighbourhood and take measures to protect themselves. In the case of the Beach neighbourhood, breaking and entering is the primary concern.

\section{SOCIOECONOMIC DEMOGRAPHICS}

A demographic analysis of the surrounding community can help identify changes in market demands, as well as opportunities for new retail uses. In fact, the alignment of market demands and retail offerings is essential to ensuring that the commercial strip is meeting its full potential. While understanding market trends has important implications for planners, comprehensive market research usually remains within the domain of large marketing firms.

As an alternative, the City tracks broad demographic trends at the ward and neighbourhood level by coding census data using administrative boundaries. However, the use of ring studies would be more effective at defining target markets and predicting customer behaviours at different scales. These studies use distance as a key factor in distinguishing specific market nuances at the local, neighbourhood, and regional scale. This makes ring studies much more versatile than traditional census profiles.

Using 1 and 3 kilometre radiuses, this study tracked various demographic characteristics, including the population size, educational attainment, home tenure, household income, place of work, mode of transportation to work, and children per household (See Appendix 3 for full Ring Study). Since the two study areas are about a kilometre apart, any ring study over 500 metres would overlap. As a result, the findings in the two study areas are quite similar and only serve an illustrative purpose.

Within a 1 kilometre radius, household income over $\$ 100,000$ is 4.6 percent higher in Kew Beach than in Woodbine Beach. This could mean that Kew Beach residents have more disposable income, and may spend more money on luxury retail merchandise or services. In contrast, Woodbine Beach has a 6.4 percent higher rate of home ownership. This may translate into a divergence in household spending habits 
with regard to home improvement and building materials. It can be inferred that a neighbourhood hardware store could potentially be profitable in Woodbine Beach.

Understanding the daytime population of the neighbourhood is also important in order to address the daytime lull which is experienced by most retail businesses outside the major employment areas. At a 1 kilometre radius, Kew Beach has 3.1 percent more residents working from home, while Woodbine Beach has 6.1 percent more children under six. This may suggest the demand for more retail and services like office supply and business-casual restaurants in Kew Beach. In contrast, new retail offerings in Woodbine Beach could cater to young children, as well as young parents/nannies; these may include educational services, like music and art lessons, or family-friendly (and stroller-friendly) restaurants and cafés.

Indicator Summary: Since the primary market for main streets are local residents, understanding local needs in convenience retail using ring studies may be of interest to businesses and BIAs. Due to the proximity of the two study areas, no definitive conclusions can be made about how well they are meeting the market demands of their local residents. As such, it may be best to use ring studies to compare socioeconomic demographics of distinct commercial strips, as opposed to precincts within those strips.

\section{CHAPTER CONCLUSIONS}

The evaluation of Kew Beach and Woodbine Beach using a set of health indicators helps advance our understanding of how the presence of mid-rise development on traditional main streets affect overall retail vibrancy. While not every indicator had a traceable impact on retail vibrancy, some important differences between the two study areas where identified with regard to retail competitiveness, retail size, retail vacancy, retail representation, and public realm. More analysis will be needed to fill the research gaps identified in some of the indicators described. However, this retail assessment provides a starting point for identifying potential planning and policy implications for the City of Toronto, as it tries to integrate mid-rise development into the existing fine grain fabric of traditional main streets, like Queen Street East. 


\section{CHAPTER 4: DISCUSSION AND RECOMMENDATIONS}

This chapter discusses key retail planning themes which have emerged from the findings presented in the previous chapter. Although some elements of this research are not generalizable to the rest of the city, the themes identified in this chapter have broader implications for retail planning at the provincial, municipal and neighbourhood level. The chapter also identifies how these neighbourhoodlevel findings might be useful for other traditional main streets, within the city's inner suburbs, which are experiencing mid-rise redevelopment pressure.

\section{Theme 1: Vague provincial policy directives regarding retail uses}

The Province of Ontario, more specifically Ontario's Growth Secretariat, does not have a clear retail planning vision for the Greater Toronto and Hamilton area. The Growth Plan does not comprehensively address retail uses in its description of complete and compact communities. Retail uses are not defined in the glossary and neither are the three retail types which make up the retail hierarchy. This lack of coherent vision means that the definitions and guidelines used for retail planning vary significantly across municipalities, further complicating the approval process for new mixed-use mid-rise development.

Without provincial policy directives, municipalities do not have the capacity to engage in holistic retail planning. The growing pressure of mixed-use development within the urban boundaries make it difficult for planners to ensure that residential and retail uses are mutually-supportive in new development and at the broader neighbourhood level. Their piecemeal approach to retail planning creates market inefficiencies and contributes to significant discrepancies, with regard to the permitted retail type, size and built form, across seemingly similar jurisdictions. It also disallows the systematic evaluation of retail performance or the implementation of retail planning interventions which could potentially improve functionality and marketability of new retail space.

\section{Recommendation 1: Provincial policies should formulate a shared vision for retail planning}

In order to achieve more comprehensive and holistic retail planning at the municipal level, provincial policy directives on retail uses must be strengthened. The Growth Plan must acknowledge retail uses as an integral component of complete and compact communities, by comprehensively addressing the concept of retail hierarchy and clearly distinguishing between the three main retail types: convenience, neighbourhood, and regional. The Plan should identify clear overarching objectives for 
retail development and address the interplay between the need to preserve the existing retail character, and the need for intensification and reurbanzaition of transit-supported corridors and urban centres.

While this recommendation is ambitious, an overarching policy approach is the preferred method to strengthening Ontario's retail sector. In fact, the retail analysis in this study borrowed health indicators from high-level retail policies developed at the national and sub-national level. These policies are evidence that retail planning and retail vibrancy assessment can be coordinated at the provincial level, leading to more consistent retail policies at the local level.

\section{Theme 2: Retail policies at the municipal level are not specific to retail type and form}

Retail planning scholars and professionals suggest that convenience, neighbourhood, and regional retail (including town centres and outlets) attract different types of demographic groups (Gibbs, 2012; Buliug and Hernandez, 2009); in turn, their retail offerings vary significantly based on the size, shopping habits and characteristics of their customer base. Toronto is a particularly interesting jurisdiction where three forms of convenience retail remain distinct and intact in certain parts of the city. These forms of convenience retail include main street, strip mall and plaza (Linovski, 2012). Each of these convenience retail forms differ due to the size and demographics of their customer base, the timing and duration of typical trips and the method of transportation typically used.

In practice, the classification of different retail types and forms is uncommon. With the exception of big-box retailers who get their own specific retail policies, Toronto's city-wide policies generally group all retail types into one big category. Retail planning is also indirectly impacted by a variety of other policies, guidelines, studies and by-laws. It is often difficult for developers to understand the relationship, hierarchy or enforceability of these planning documents, which can create a steep learning curve for developers who are navigating a new regulatory terrain. For example, certain streets in the city have been identified as priority retail streets (J.C. Williams Group, 2015, b), however it is not clear how these streets are chosen and what the City is doing to make them a priority. Where possible, simplification of the planning policy and regulatory framework should be attempted to help developers navigate the application approval process. In the long-term, the city's needlessly complicated approach to retail planning can be streamlined through the use of comprehensive retail guidelines.

Recommendation 2: Municipal retail planning guidelines should be based on retail type and form

After the formulation of a shared vision for retail planning at the provincial level (Recommendation 1), the City of Toronto should establish city-wide guidelines based on retail type and 
form, as opposed to retail location. It should have retail planning guidelines for convenience, neighbourhood and regional shopping areas. Given that the retail form of shopping areas usually dictates the customer base, these guidelines should also include distinct policies for the three main forms of convenience retail. Policies regarding preferred retail types, as well as rental size, retail to service ratio, parking requirements, and accessory uses for new development should be standardized for each retail type and form.

Although it may be difficult to categorize certain retail forms, these guidelines could potentially evolve as new retail forms emerge (e.g. retail in mid-rise buildings). It should be noted that these retail planning policy guidelines are not meant to replace urban design guidelines or official plan policies; instead they are meant to systematically improve the conditions which facilitate retail vibrancy by systematically planning for common retail type and form.

These municipal retail planning guidelines should be developed by the city in consultation with BIAs, commercial property owners, retail tenants, real estate developers and other stakeholders. The roles and responsibilities of each of these stakeholders should be clarified in the guidelines to ensure the accountability of key actors. Moreover, the creation of the guidelines will also facilitate the identification of obstacles to comprehensive retail planning. One such obstacle may be that BIAs have varying degrees of financial and other resources. As such, if it is decided that BIAs should play an active role in improving neighbourhood retail vibrancy, new strategies may be needed to build their capacity.

Standardized evaluation criteria, with appropriate targets, can also be included in the guidelines to facilitate the future assessment of relevant retail vibrancy indicators for the city's distinct retail types and forms. The findings from these assessments can be used to determine how different commercial areas are performing and where future planning intervention is needed. In addition, where urban design guidelines do not already exist, brief built form and streetscape policies can be included in the guidelines for each retail form. This will pre-emptively discourage unwanted built form elements, like arcades and colonnades, in areas where new development has not picked up enough momentum to warrant their own urban design guidelines (e.g. development on smaller arterial and collector roads).

\section{Theme 3: Urban design guidelines are insufficient to ensure retail vibrancy}

In Toronto, urban design guidelines have been established to encourage and shape mid-rise and other new development. They offer a patchwork of policies which reflect the temporal and spatial context of the area they are intended for. Their primary objective is to create a consistent and pedestrian-oriented streetscape aesthetic, while ensuring the smooth transition of the built form to adjacent land-uses. These 
guidelines are usually enforced by planners who use them as a primary tool to evaluate development proposals; in turn, some elements indirectly facilitate the improvement of retail vibrancy. The elements include restricting at grade height, requiring generous front setbacks, mandating amenities needed for certain retail uses (e.g. proper ventilation for restaurant uses) and encouraging certain retail types (e.g. restaurants and cafés). Nevertheless, urban design guidelines focus on dictating the "look and feel" of development (J.C. Williams Group, 2015, p.16 b) and are too broad to create conditions which attract and retain a vibrant retail mix.

These requirements are also reactive, as they are often based on the lessons learned from previous mistakes. Urban design guidelines are static and inflexible, since any guideline amendments must go through a time-consuming and bureaucratic City Council approval process. Moreover, new development requiring zoning by-law and official plan amendments are usually negotiated between developers and the City on a case-by-case basis. These negotiations impede the predictability of the development application process, producing varied results and frequent appeals to the Ontario Municipal Board. Therefore, the success of retail often hangs in the balance of these negotiations. In order to create a more consistent and transparent approval process, a more systematic approach to retail requirements in new developments should be taken.

\section{Recommendation 3: Coordinate a retail replacement policy}

While coordinated provincial and municipal retail planning (Recommendation 1 and 2) is still at its infancy, a retail replacement policy should be used by the City of Toronto as an interim strategy to facilitate the integration of new development on existing main streets. Since mid-rise development often replaces existing main street retail along major avenues, community planners should work to ensure that new proposals feature "retail replacement" units which are of a similar quality and size.

For example, if a developer is demolishing four retail units to build a new mid-rise development the design should contain a requirement to include four retail units which do not exceed the floor area of the largest retail unit demolished. This intervention will preserve the existing stock of smaller retail units on main streets, and could potentially oblige developers to give the evicted small business owners an opportunity to acquire retail space in the new development once it is completed. It also contributes to a more predictable and consistent process for determining the appropriate amount of retail space in new developments. 
One of the key outstanding challenges in municipal retail planning is how to facilitate the improvement of retail vibrancy in developments which have already been built. The first obstacle to deciding on the proper intervention is identifying who should be responsible for filling these retail vacancies: the city, the business improvement area, the property owner, the real estate broker or someone else entirely. This issue is particularly challenging in the Beach because of the absenteeism of property owners in the neighbourhood and the limited capacity of the Beach Village BIA. Since the real estate portfolios of property owners often include multiple properties, they may be less concerned with filling individual retail units as long as the overall portfolio remains profitable. As a result, finding tenants for vacant commercial space falls to business improvement areas.

Unfortunately, the involvement of business improvement areas in the recruitment and retention of businesses is highly variable across the city. Ethnic commercial strips in the city are often linked through their cultural identity; for example, Chinatown BIA has a very strong network of Vietnamese and Chinese businesses, and uses this network to recruit new ethnic businesses to the area (Uneke, 1996; Phan and Luk, 2005). In contrast, the Beach Village BIA is heavily invested in neighbourhood event and marketing initiatives, and does not have the capacity or resources to play an active role in recruiting new businesses. Barriers like a largely inactive membership, anonymity of property owners, and other information gaps make it difficult for the BIA to make meaningful changes.

\section{Recommendation 4: Employ innovative approaches to fill persistently vacant commercial space}

Many mid-rise developments along main streets in inner city suburbs are continuing to experience high commercial vacancy. In the absence of provincial and municipal direction on retail planning (Recommendation 1 and 2), ad hoc initiatives led by various stakeholders can be used to fill commercial spaces that are persistently vacant. Although some factors like retail price and ownership structure act as potential barriers to entry for small independent businesses, vacant properties should be proactively filled by attracting temporary or institutional uses.

The City should actively seek to revise the way in which it implements Ontario's property tax rebate program. Redesigning the program to encourage property owners to be proactive in finding of new tenants could inspire the use of more flexible and short-term leasing agreements. To the same end, the City can also use MPAC records (including property owner, address and size) to create an interactive tool which tracks vacant properties and their specifications across the city. This interactive inventory can help facilitate the use of vacant space for more pop-up uses, as well as for other temporary or event purposes 
like movie shoots, conferences and conventions, and art and cultural productions. By bringing together property owners and people seeking retail space, the City can jumpstart its implementation of its Collaborating for Competitiveness strategic plan. Business improvement areas and real estate brokers can also benefit from this vacant commercial space inventory. They can use this tool to advertise properties that are suitable for pop-up and other temporary uses. In fact, the inventory can aid resource-constrained local stakeholders in attracting businesses which contribute to a competitive retail mix, and inspiring new and innovative solutions to alleviate high and persistent vacancy rates.

Given that business improvement areas and resident associations have limited resources, partnering in local initiatives could be a way to build capacity and expand professional networks. These partnerships can help the Beach Village BIA collect data about retail supply, customer shopping behaviour and local resident needs. The data can then inform future interventions like targeted retailer recruitment strategies and streetscape improvements.

Depending on the size and layout of the space, property owners (and their real estate brokers) can also take advantage of Ontario's growing support for the establishment of neighbourhood-centric community hubs. The new Community Hub Framework and Action Plan advocates for the integration and co-location of health and social services in neighbourhoods which have insufficient social infrastructure (Government of Ontario, 2015). This intervention will require the establishment of a long-term publicprivate partnership between the property owner and the city and/or province; thus, securing reliable and stable tenants for a property which may otherwise continue to remain vacant. On the other hand, the public service provider benefits from a centrally-located, highly-visible and transit-accessible location. While this initiative will not necessarily improve retail vibrancy, it could indirectly impact the commercial strip by acting as an important neighbourhood anchor. However, further research will be required to identify what social services are needed in the Beach, which service providers are embracing the community hub approach to service provision, and if there are any suitable retail units which can accommodate these services.

\section{Broader Application of Findings}

This research took the first step in understanding the context of the Beach neighbourhood and pinpointing the underlying factors contributing to the difference in retail vibrancy between two precincts; one characterised by mid-rise development and the other exhibiting fine grain retail. The fine grain retail character observed in the Beach is also present in various inner city neighbourhoods, making the findings and implications presented in this study relevant to other parts of Toronto. Main streets, like Kingston 
Road, Queen Street West and Queen Street East (Riverside-Leslieville), are particularly similar in character to the study area and are also experiencing mid-rise infill development pressure. Moreover, the methodology used to evaluate retail vibrancy can be more broadly used in neighbourhood retail studies across the city to compare and contrast the effectiveness of different neighbourhoods or built form types in enhancing retail success.

While "retail vibrancy" remains a slippery term in both the academic and professional literature, planners are adopting new ways of measuring it. They are paying closer attention to how differences in the built form affect retail vibrancy, what partnerships can be used to preserve and enhance existing retail, and what planning strategies or tools will be necessary to effectively integrate new retail into the city's inner suburbs. Nevertheless, comprehensive retail planning is faced with a myriad of new challenges. These include the blurring of retail hierarchies, changing demographic trends and spending habits, and evolving complexity of urban city planning. In fact, new advances in technology (e.g. e-commerce) have forever altered where, when, and how people shop. There has never been so much choice - the world is our marketplace. All the same, retail on main streets and other arterial roads are the backbone of Toronto's economy. Consequently the City of Toronto has a role to play in ensuring that its entire retail sector stays competitive; this includes both the businesses located in fine grain two-storey buildings and those in 11-storey mid-rises. 


\section{APPENDICES}

\section{APPENDIX 1: Additional Information about CSCA data}

Table 1: Total Number of Retail Units in the Study Areas

\begin{tabular}{|lrrrrrrrrrrrr|} 
& $\mathbf{2 0 0 5}$ & $\mathbf{2 0 0 6}$ & $\mathbf{2 0 0 7}$ & $\mathbf{2 0 0 8}$ & $\mathbf{2 0 0 9}$ & $\mathbf{2 0 1 0}$ & $\mathbf{2 0 1 1}$ & $\mathbf{2 0 1 2}$ & $\mathbf{2 0 1 3}$ & $\mathbf{2 0 1 4}$ & $\mathbf{2 0 1 5}$ & Average \\
\hline Woodbine & 20 & 21 & 19 & 19 & 19 & 19 & 35 & 30 & 30 & 31 & 40 & 33.2 \\
\hline Kew & 54 & 59 & 62 & 64 & 71 & 70 & 77 & 71 & 71 & 75 & 74 & 73.6 \\
\hline
\end{tabular}

Data Source: CSCA, 2015

Table 2: Omitted Records from the Study Areas

\begin{tabular}{|lllll|}
\hline Store ID & Company Name & Address & Size & NAICS Category \\
\hline 812114 & Beach Kidz Kutz & 1826A Queen St E & 700 & Personal and laundry services \\
\hline 443143 & $\begin{array}{l}\text { Classic Fire Place And } \\
\text { Gourmet Grills }\end{array}$ & 1828 Queen St E & 760 & $\begin{array}{l}\text { Electronics and appliance } \\
\text { stores }\end{array}$ \\
\hline 812320 & Kew Beach Cleaners & 1830 Queen St E & 800 & Personal and laundry services \\
\hline 812116 & Shear Madness Hair Studio & 1832 Queen St E & 860 & Personal and laundry services \\
\hline 522310 & Welbanks Mortgage Group & 1834 Queen St E & 800 & $\begin{array}{l}\text { Credit intermediation and } \\
\text { related activities }\end{array}$ \\
\hline
\end{tabular}

Data Source: CSCA, 2015

Table 3: Number of Turnovers per Retail Unit between 2011 and 2015

\begin{tabular}{|lrrrr|} 
& \multicolumn{2}{c}{ Woodbine Beach } & \multicolumn{2}{c|}{ Kew Beach } \\
\hline & $\#$ & $\%$ & $\#$ & $\%$ \\
\hline 1 & 7 & $18 \%$ & 19 & $26 \%$ \\
\hline 2 & 3 & $8 \%$ & 8 & $11 \%$ \\
\hline 3 & 0 & $0 \%$ & 0 & $0 \%$ \\
\hline 4 & 0 & $0 \%$ & 0 & $0 \%$ \\
\hline 5 & 1 & $3 \%$ & 0 & $0 \%$ \\
\hline Total & 11 & $28 \%$ & 0 & $36 \%$ \\
\hline
\end{tabular}

* Only the retail units that existed in 2015 were used for the analysis.

Data Source: CSCA, 2015 


\section{APPENDIX 2: Interview Questions for Stakeholders}

\section{Retail Tenants}

Introductory Questions

1. Tell me a little bit about your business?

a. When established? How many locations?

b. Do you feel like there are regular peak times?

2. Why did you choose to locate here?

a. This particular property

b. The Beaches neighbourhood

Satisfaction with Characteristics and Location of Retail Space

3. Is there anything you would change about the unit or the location you are in?

4. Are you involved with the Beach Village BIA?

Characterizing the Changes in the Beaches

5. What do you feel are the natural boundaries of the Beaches neighbourhood?

6. Have you observed any changes or trends in the Beaches retail strip?

7. Are there any other comments you would like to make?

\section{Real Estate Agents}

Introductory Questions

1. Tell me a little bit about your business

a. When established? How many properties do you manage?

2. What kind of retail tenants do you typically lease to?

Vacancy Questions

3. Has vacancy or high turnover been an issue for any of your property listings in the Beaches?

4. How do you normally advertise retail vacancies?

Satisfaction with Location of Property Listings

5. Do you feel you face any challenges as a real estate agent in the Beaches neighbourhood?

6. Are you involved with the Beach Village BIA?

Characterizing the Changes in the Beaches

7. Have you observed any changes or trends in the Beaches retail strip?

8. Are there any other comments you would like to make? 


\section{Beach Village BIA}

Introductory Questions

1. What are the main priorities of the Beach Village BIA?

2. Have there been any challenges in meeting these objectives of the BIA? Are unique to the Beaches neighbourhood or common in all BIAs?

3. Has the BIA undergone any recent changes?

Attracting Retail Tenants/Vacancy Questions

4. What kind of strategies does the Beaches BIA use to attract and retain retail businesses?

5. Do you feel that the Beaches retail strip carters to primarily local residents, regional visitors (Toronto/GTA), or tourists?

6. Are you aware of any parts of the Beaches retail strip that have experienced high vacancy rates or turnover rates?

a. Does the BIA play any direct or indirect role in reducing those rates?

Characterizing the Changes in the Beaches

7. Do you feel that the three Beach Precincts are distinct from one another, or are they connected and interdependent?

8. Have you observed any changes or trends in the Beaches retail strip?

a. Do you feel that new developments have preserved and reinforced the character of the neighbourhood?

b. In your opinion, how successful has retail in newer mid-rise buildings been?

9. Are there any other comments you would like to make?

\section{Community Planners}

\section{Introductory Questions}

1. Do you feel that the city's policies and urban design guidelines have successfully protected existing retail main streets from unsuitable built form?

a. How about when we are talking about Queen St East specifically?

\section{Beaches Questions}

2. How would you characterise the Beaches retail strip?

3. Do you feel that the Beaches retail strip carters to primarily local residents, regional visitors (Toronto/GTA), or tourists?

Characterizing the Changes in the Beaches

4. How would you describe the character of the retail along Queen St E in the Beaches neighbourhood?

5. Do you feel that the three Beach Precincts are distinct from one another, or are they the connected and interdependent?

6. Have you observed any changes or trends in the Beaches retail strip?

a. Do you feel that new development have preserved and reinforced the character of the neighbourhood?

b. In your opinion, how successful has retail in newer mid-rise buildings been?

7. Are there any other comments you would like to make? 


\section{APPENDIX 3: Demographic Ring Study (1 and 3 kilometre buffer)}

*From the most central disseminations area of each study area

Table 1: Total Population, 2011

\begin{tabular}{|lllllll|} 
& \multicolumn{2}{c}{ Woodbine Beach } & \multicolumn{2}{c|}{ Kew Beach } & Toronto & Canada \\
\hline & $1 \mathrm{~km}$ & $3 \mathrm{~km}$ & $1 \mathrm{~km}$ & $3 \mathrm{~km}$ & & \\
\hline Population & 15,489 & 81,920 & 16,070 & 74,231 & $2,615,060$ & $33,476,688$ \\
\hline
\end{tabular}

Data Source: Environics Analytics, n.d. using Census, 2011.

Table 2: Population 15 Years or Over by Educational Attainment, by percentage, 2011

\begin{tabular}{|lcccccc|}
\hline & Woodbine Beach & \multicolumn{2}{c|}{ Kew Beach } & Toronto & Canada \\
\hline & $1 \mathrm{~km}$ & $3 \mathrm{~km}$ & $1 \mathrm{~km}$ & $3 \mathrm{~km}$ & & \\
\hline No certificate, diploma or degree & $10.5 \%$ & $15.5 \%$ & $9.1 \%$ & $14.1 \%$ & $17.5 \%$ & $20.1 \%$ \\
\hline High school diploma or equivalent & $19.2 \%$ & $21.1 \%$ & $19.8 \%$ & $21.6 \%$ & $24.1 \%$ & $25.6 \%$ \\
\hline $\begin{array}{l}\text { Apprenticeship, College, CEGEP } \\
\text { or trades certificate or diploma }\end{array}$ & $22.1 \%$ & $20.6 \%$ & $18.7 \%$ & $21.1 \%$ & $20.3 \%$ & $29.1 \%$ \\
\hline $\begin{array}{l}\text { University certificate, diploma or } \\
\text { degree at bachelor level or above }\end{array}$ & $48.2 \%$ & $42.9 \%$ & $52.3 \%$ & $43.3 \%$ & $38.1 \%$ & $25.3 \%$ \\
\hline
\end{tabular}

Data Source: Environics Analytics, n.d. using Census, 2011.

* Grey represents more than 3 percent difference

Table 3: Occupied Private Dwellings by Tenure, by percentage, 2011

\begin{tabular}{|lcccccc|}
\hline & \multicolumn{2}{c}{ Woodbine Beach } & \multicolumn{2}{c|}{ Kew Beach } & Toronto & Canada \\
\hline & $1 \mathrm{~km}$ & $3 \mathrm{~km}$ & $1 \mathrm{~km}$ & $3 \mathrm{~km}$ & & \\
\hline Rented & $34.4 \%$ & $38.0 \%$ & $40.8 \%$ & $37.4 \%$ & $45.4 \%$ & $30.6 \%$ \\
\hline Owned & $65.6 \%$ & $62.0 \%$ & $59.2 \%$ & $62.6 \%$ & $54.6 \%$ & $69.0 \%$ \\
\hline
\end{tabular}

Data Source: Environics Analytics, n.d. using Census, 2011.

* Grey represents more than 3 percent difference

Table 4: Household Income, by percentage, 2011

\begin{tabular}{|lrrrrrr|}
\hline & \multicolumn{2}{c}{ Woodbine Beach } & \multicolumn{2}{c|}{ Kew Beach } & Toronto & Canada \\
\hline & $1 \mathrm{~km}$ & $3 \mathrm{~km}$ & $1 \mathrm{~km}$ & $3 \mathrm{~km}$ & & \\
\hline Household Income $\$ 0$ to $\$ 19,999$ & $12.8 \%$ & $15.8 \%$ & $12.4 \%$ & $15.2 \%$ & $17.1 \%$ & $13.1 \%$ \\
\hline Household Income $\$ 20,000$ to $\$ 39,999$ & $15.3 \%$ & $16.5 \%$ & $13.8 \%$ & $16.2 \%$ & $19.6 \%$ & $18.5 \%$ \\
\hline Household Income $\$ 40,000$ to $\$ 59,999$ & $14.5 \%$ & $14.4 \%$ & $13.7 \%$ & $14.5 \%$ & $16.8 \%$ & $17.4 \%$ \\
\hline Household Income $\$ 60,000$ to $\$ 79,999$ & $13.2 \%$ & $11.9 \%$ & $12.1 \%$ & $12.5 \%$ & $13.0 \%$ & $14.5 \%$ \\
\hline Household Income $\$ 80,000$ to $\$ 99,999$ & $9.7 \%$ & $9.6 \%$ & $8.5 \%$ & $9.7 \%$ & $9.5 \%$ & $11.3 \%$ \\
\hline Household Income $\$ 100,000$ and over & $34.6 \%$ & $31.8 \%$ & $39.2 \%$ & $31.8 \%$ & $24.1 \%$ & $25.3 \%$ \\
\hline
\end{tabular}

Data Source: Environics Analytics, n.d. using Census, 2011.

* Grey represents more than 3 percent difference 
Table 5: Labour Force by Place of Work, by percentage, 2011

\begin{tabular}{|lccccrr|}
\hline & \multicolumn{2}{c}{ Woodbine Beach } & \multicolumn{2}{c|}{ Kew Beach } & Toronto & Canada \\
\hline & $1 \mathrm{~km}$ & $3 \mathrm{~km}$ & $1 \mathrm{~km}$ & $3 \mathrm{~km}$ & & \\
\hline Worked at usual place & $78.2 \%$ & $80.7 \%$ & $75.6 \%$ & $80.3 \%$ & $81.5 \%$ & $81.5 \%$ \\
\hline No fixed workplace address & $10.7 \%$ & $9.9 \%$ & $10.4 \%$ & $10.0 \%$ & $11.1 \%$ & $11.3 \%$ \\
\hline Worked outside Canada & $0.3 \%$ & $0.1 \%$ & $0.0 \%$ & $0.1 \%$ & $0.5 \%$ & $0.4 \%$ \\
\hline Worked at home & $10.8 \%$ & $9.4 \%$ & $13.9 \%$ & $9.6 \%$ & $6.9 \%$ & $6.9 \%$ \\
\hline
\end{tabular}

Data Source: Environics Analytics, n.d. using Census, 2011.

* Grey represents more than 3 percent difference

Table 6: Labour Force by Mode of Transportation, by percentage, 2011

\begin{tabular}{|lrrrrrr|} 
& \multicolumn{2}{c}{ Woodbine Beach } & \multicolumn{2}{c|}{ Kew Beach } & Toronto & Canada \\
& $1 \mathrm{~km}$ & $3 \mathrm{~km}$ & $1 \mathrm{~km}$ & $3 \mathrm{~km}$ & & \\
\hline Car, truck or van - as a driver & $51.1 \%$ & $42.3 \%$ & $52.4 \%$ & $44.3 \%$ & $48.3 \%$ & $74.0 \%$ \\
\hline Car, truck or van - as a passenger & $5.6 \%$ & $4.5 \%$ & $5.2 \%$ & $4.2 \%$ & $4.6 \%$ & $5.6 \%$ \\
\hline Public transit & $31.4 \%$ & $41.1 \%$ & $30.2 \%$ & $40.2 \%$ & $36.5 \%$ & $12.0 \%$ \\
\hline Walked & $6.2 \%$ & $6.0 \%$ & $6.6 \%$ & $5.7 \%$ & $7.3 \%$ & $5.7 \%$ \\
\hline Bicycle & $3.7 \%$ & $4.3 \%$ & $4.0 \%$ & $3.8 \%$ & $2.2 \%$ & $1.3 \%$ \\
\hline Other methods & $2.0 \%$ & $1.8 \%$ & $1.7 \%$ & $1.8 \%$ & $1.2 \%$ & $1.3 \%$ \\
\hline
\end{tabular}

Data Source: Environics Analytics, n.d. using Census, 2011.

Table 7: Households with Children, by percentage, 2011

\begin{tabular}{|lcccccc|}
\hline & Woodbine Beach & \multicolumn{2}{c|}{ Kew Beach } & Toronto & Canada \\
\hline & $1 \mathrm{~km}$ & $3 \mathrm{~km}$ & $1 \mathrm{~km}$ & $3 \mathrm{~km}$ & & \\
\hline Children under 6 years of age & $31.1 \%$ & $27.0 \%$ & $25.0 \%$ & $26.3 \%$ & $20.9 \%$ & $22.2 \%$ \\
\hline Children between 6 and 14 years & $32.6 \%$ & $31.1 \%$ & $34.2 \%$ & $32.2 \%$ & $29.3 \%$ & $33.3 \%$ \\
\hline Children between 15 and 17 years & $9.5 \%$ & $10.0 \%$ & $10.6 \%$ & $10.3 \%$ & $10.7 \%$ & $12.4 \%$ \\
\hline Children between 18 and 24 years & $17.5 \%$ & $19.0 \%$ & $20.1 \%$ & $19.1 \%$ & $21.2 \%$ & $20.7 \%$ \\
\hline Children 25 years and older & 9.3 & $13.0 \%$ & $10.2 \%$ & $12.1 \%$ & $17.9 \%$ & $11.3 \%$ \\
\hline
\end{tabular}

Data Source: Environics Analytics, n.d. using Census, 2011.

* Grey represents more than 3 percent difference 


\section{APPENDIX 4: Additional Photographs of Study Areas}

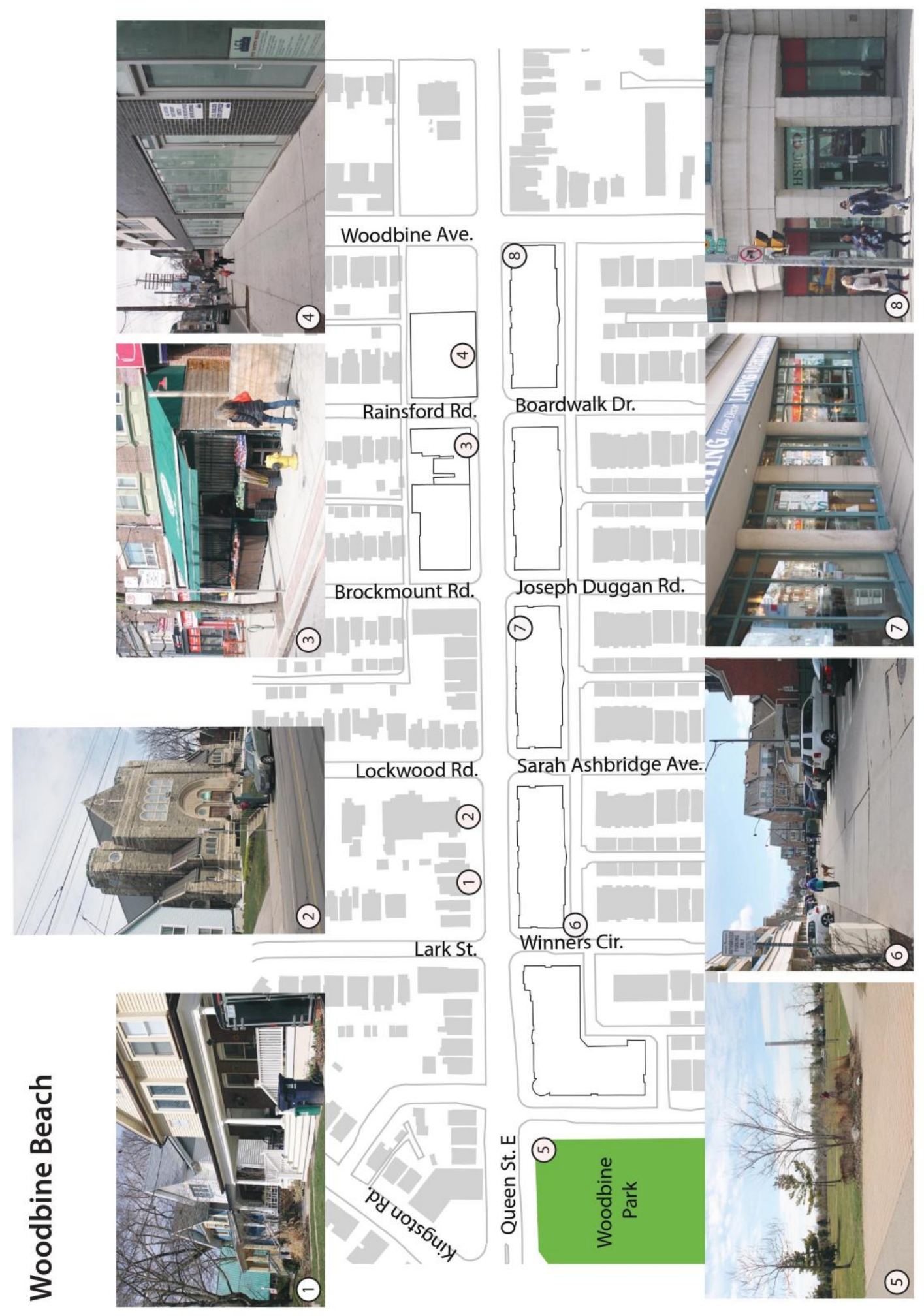




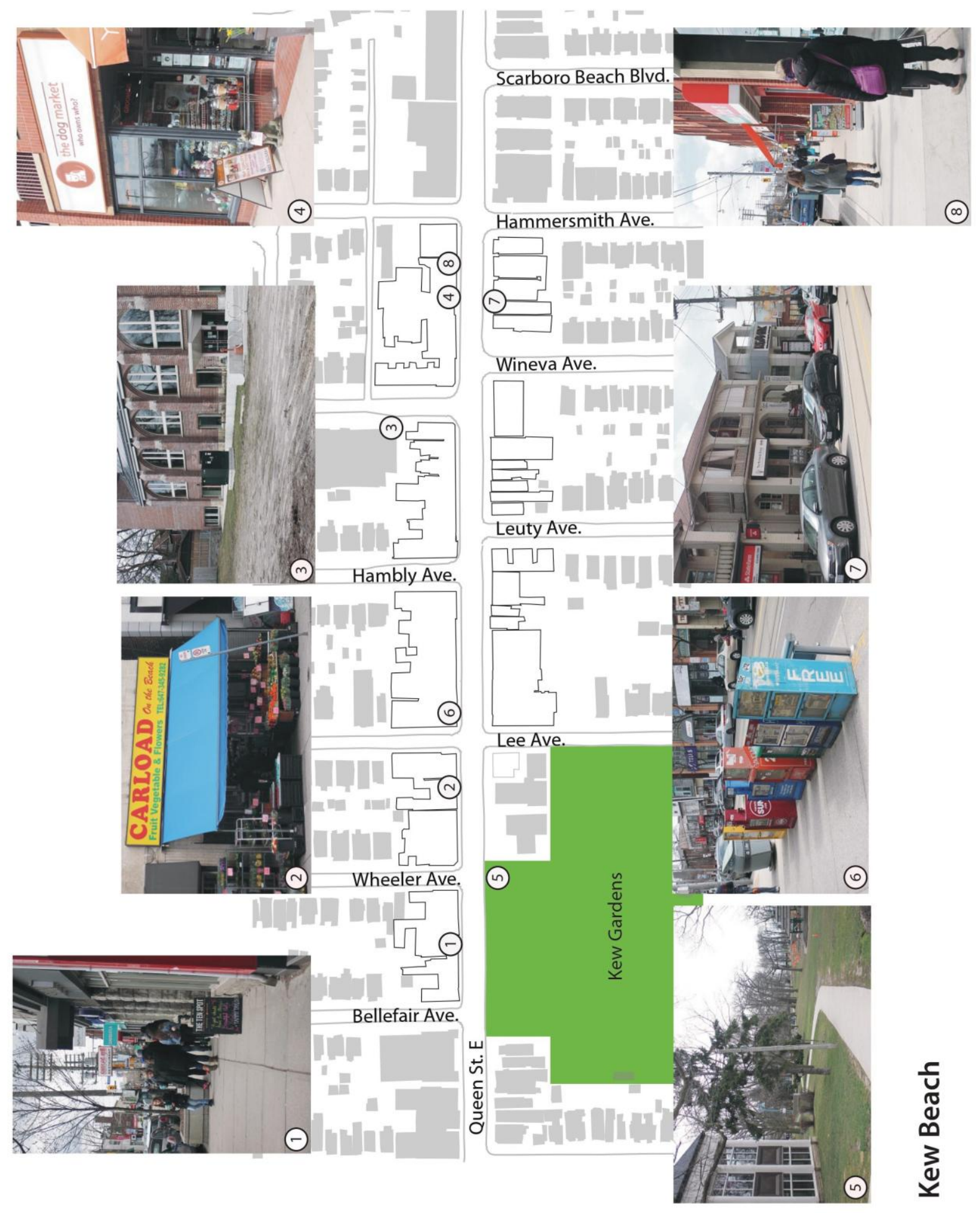




\section{REFERENCES}

Alexander, D. and Shaw, P. (2012). Say goodbye to small retail: should we care? Plan Canada, 52(2), 2633.

Armstrong, J. and Armstrong K. (n.d.). 1829,1797,1765,1733,1863 Queen St E - The beach condos. Retrieved (March 3, 2016) from http://www.jarrodarmstrong.com/1829-1797-1765-1733-1863Queen-St-E-The-Beaches-Condos

Baker, B. (2009). Retail property conference in the U.K. addresses downturn, Urban Land, 68(1), 23-24.

Baker, R.G. and Wood, S. (2010). Towards robust development of retail planning policy: maintaining the viability and vitality of main street shopping precincts. Geographical Research, 48(1), 65-74. DOI: $10.1111 / \mathrm{j} .1745-5871.2009 .00622 . x$

Barc, A. (2010, September 5). Nostalgia tripping: Toronto's streetcar suburbs. Retrieved (March 3, 2016) from http://www.blogto.com/city/2010/09/nostalgia_tripping_torontos_streetcar_suburbs/

Brook McILroy Planning + Urban Design/Pace Architects. (2010). Avenues and mid-rise buildings study. Prepared for the City of Toronto. Retrieved (March 3, 2016) from http://www1.toronto.ca/wps/portal/contentonly?vgnextoid=7238036318061410VgnVCM100000 71d60f89RCRD

Brook McILroy Planning + Urban Design/Pace Architects. (2010 July) b. Avenues and mid-rise buildings study area map. Prepared for the City of Toronto. Retrieved (March 3, 2016) from https://www1.toronto.ca/City\%20Of\%20Toronto/City\%20Planning/Urban\%20Design/Midrise/midrise-Avenues-Area-Map.pdf

Brown, R. (2012). Barriers to mid-rise development in Toronto. Major Research Paper prepared for Ryerson University. Retrieved from Proquest.

Buliung, R. and Hernandez, T. (2009, April) Places to shop and places to grow. Neptis Foundation. Retrieved (March 3, 2016) from http://www.neptis.org/sites/default/files/toronto_metropolitan_region_places_to_shop_places_to_ grow/places_to_shop_web_20090428_0.pdf

Campbell, M. and Myrvold, B. (1988). The Beach in pictures, 1793-1932. (Local History Handbook No. Six) Toronto: Toronto Public Library Board.

Carmona, M. (2015). London's local high streets: the problems, potential and complexities of mixed street corridors. Progress in Planning, 100, 1-84. DOI: http://dx.doi.org/10.1016/j.progress.2014.03.001

City of Toronto. (2009, May 25). 1864 to 1876 Queen St E - rezoning application and demolition application under Municipal Code 667 - final report. Retrieved (March 3, 2016) from http://www.toronto.ca/legdocs/mmis/2009/te/bgrd/backgroundfile-21942.pdf

City of Toronto. (2012, January 10). Request for visioning study of Queen Street East between Coxwell Avenue and Neville Park Boulevard. Item presented for consideration at Toronto and East York 
Community Council. Retrieved (March 3, 2016) from

http://app.toronto.ca/tmmis/viewAgendaItemHistory.do?item=2012.TE12.123

City of Toronto. (2012, November) b. Queen Street East Coxwell Avenue to Nursewood Road: City of Toronto Urban Design Guidelines. Retrieved (March 3, 2016) from http://www.toronto.ca/legdocs/mmis/2012/te/bgrd/backgroundfile-51604.pdf

City of Toronto. (2012, April 26) c. 1960 and 1962 Queen St E-zoning amendment application - final report. Item presented for consideration at Toronto and East York Community Council. Retrieved (March 3, 2016) from http://www.toronto.ca/legdocs/mmis/2012/te/bgrd/backgroundfile46833.pdf

City of Toronto. (2013). Zoning By-law no. 569-2013. (Toronto, ON).

City of Toronto. (2013). Zoning By-law no. 607-2013. (Toronto, ON).

City of Toronto. (2014, March 28). Re-designing the vacant commercial and industrial tax relief Program to stimulate economic growth (Collaborating for competitiveness, implementation action 8). Item presented for consideration at Economic Development Committee. Retrieved (March 3, 2016) from http://www.toronto.ca/legdocs/mmis/2014/ed/bgrd/backgroundfile-68227.pdf

City of Toronto. (Consolidated 2010). Zoning By-law no. 438-86. (Toronto, ON).

City of Toronto. (n.d.). Urban design - civic improvements: streetscape manual street index. Retrieved (March 3, 2016) from http://wx.toronto.ca/inter/plan/streetscape.nsf

City of Toronto. (n.d.) b. Property tax rebate for vacant commercial and industrial buildings. Retrieved (March 3, 2016) from http://www1.toronto.ca/wps/portal/contentonly?vgnextoid=df25ff0e43db1410VgnVCM1000007 1d60f89RCRD

Conrad, S.T. (2010). Successful urban mixed-use development: a cautionary tale of two cities. Dissertation prepared for Arizona State University. Retrieved from Proquest.

Crosby, N., Hughes, C., Lizieri, C. and Oughton, M. (2005). A message from the oracle: the land use impact of a major in-town shopping centre on local retailing. Journal of Property Research, 22(23), 245-265. DOI: 10.1080/09599910500453848

Dalglish, B. (2014, January 20). Mid-rise buildings challenge Toronto developers, city. The Globe and Mail. Retrieved (March 3, 2016) from http://www.theglobeandmail.com/report-onbusiness/industry-news/property-report/mid-rise-buildings-challenge-toronto-developerscity/article16410177/

Department of the Environment, Community and Local Government. (2012, April). Guidelines for Planning Authorities Retail Planning. Government of Ireland. Retrieved (March 3, 2016) from http://www.environ.ie/sites/default/files/migratedfiles/en/Publications/DevelopmentandHousing/Planning/FileDownLoad\%2C30026\%2Cen.pdf

Ellen, I. G., Schwartz, A.E., and Voicu, I. (2007). The impact of business improvement districts on property values: evidence from New York City. Brookings-Wharton Papers on Urban Affairs. 
Retrieved (March 3, 2016) from

http://furmancenter.org/files/publications/ImpactofBIDcombined_000_1.pdf

Funderburk, T. (2004). Avoiding pitfalls of mixed-use projects. Urban Land, 63(5), 36-38.

Gibbs, R.J. (2012). Principles of urban retail planning and development. Hoboken, New Jersey: John Wiley \& Sons Inc.

Government of Ontario. (2010). Business improvement area handbook. Retrieved (March 3, 2016) from http://www.mah.gov.on.ca/Asset7396.aspx

Government of Ontario. (2015, August). Community hubs in Ontario: A strategic framework and action plan. Retrieved (March 3, 2016) from https://www.ontario.ca/document/community-hubsrecommendations-and-action-plan

Grant, J. (2002) Mixed use in theory and practice: Canadian experience with implementing a planning principle. Journal of the American Planning Association, 68(1), 71-84. DOI: $10.1080 / 01944360208977192$

Grant, J. and Perrott, K. (2011). Where is the café? The challenge of making retail uses viable in mixeduse suburban developments. Urban Studies, 48(1), 177-195. DOI: 10.1177/0042098009360232

Griffiths, S., Vaughan, L., Haklay, M., \& Jones, C. (2008). The sustainable suburban high street: A review of themes and approaches. Geography Compass, 2(4), 1155-1188.

Hernandez, T. (2007). Lifestyle centres in Canada: 2007. CSCS Research Letter 2007-11. Toronto: Centre for the Study of Commercial Activity, Ryerson University.

Hendershott, P.H., Jennen, M. and MacGregor, B.D. (2013). Modeling space market dynamics: an illustration using panel data for US retail. Journal of Real Estate Finance and Economics, 47, 659-687. DOI: 10.1007/s11146-013-9426-z

Hoyt, L.M. (2003). The business improvement district: An internally diffused approach to revitalization. Retrieved (March 3, 2016) from http://www.lorlenehoyt.com/yahoo_site_admin/assets/docs/Hoyt_IDA.325174429.pdf

Hoyt, L. M. (2005). Do business improvement district organizations make a difference? Crime in and around commercial areas in Philadelphia. Journal of Planning Education and Research, 25: 185199. DOI: $10.1177 / 0739456 X 05279276$

J.C. Williams Group. (2014, February). Evaluating large retail developments near pedestrian shopping areas in Toronto. Prepared for City Planning in the City of Toronto. Retrieved (March 3, 2016) from https://www1.toronto.ca/City\%20Of\%20Toronto/City\%20Planning/Community\%20Planning/Fil es/pdf/B/Bathurst_Study_JCWG\%20Final.pdf

J.C. Williams Group. (2015, December). TOCore retail and service commercial land use study. Prepared for City Planning in the City of Toronto. Retrieved (March 3, 2016) from https://www1.toronto.ca/City\%20Of\%20Toronto/City\%20Planning/Community\%20Planning/Fil es/pdf/B/Bathurst_Study_JCWG\%20Final.pdf 
J.C. Williams Group. (2015, June) b. TOCore retail and service commercial land use study presentation. Prepared for City Planning in the City of Toronto. Retrieved (March 3, 2016) from https://www1.toronto.ca/City\%20Of\%20Toronto/City\%20Planning/Core/File/pdf/RETAIL_TOc oreJCWilliamsExistingConditionsPresentation.pdf

Kajalo, S. and Lindblom, A. (2015). Creating a safe and pleasant shopping environment: A retailer's view. Property Management, 33(3), 275-286. DOI: 10.1108/PM-10-2014-0042

Katyoka, M. and Wyatt, P. (2008). An investigation of the nature of vacant commercial and industrial property. Planning, Practice \& Research, 23(1), 125-145. DOI: 10.1080/02697450802076704

Legal Line. (n.d.). Rent increase. Retrieved (March 3, 2016) from http://www.legalline.ca/legalanswers/rent-increases/

Linovski, O. (2012). Beyond aesthetics: assessing the value of strip mall retail in Toronto. Journal of Urban Design, 17(1), 81-99. DOI: http://dx.doi.org/10.1080/13574809.2011.646247

Macht, W. P. (2009). Bringing downtown to Charlotte's suburbs. Urban Land, 68(1), 94-95.

Ministry of Public Infrastructure and Renewal. (Consolidated 2013). Growth plan for the greater golden horseshoe (Toronto, ON): Queen's Printer for Ontario.

Mirel, D. (2010). Creative Space: property managers tackle vacancy rates by exploring new leasing options and cost structure. Journal of Property Management, 75(4), 36-41.

Mitchell, J. (2001). Business improvement districts and the 'new' revitalization of downtown. Economic Development Quarterly, 15(2), 115-123.

Murray, A. and Hernandez, T. (2015). Downtown retailing in Canada's Vetcom Markets. Toronto: Centre for the Study of Commercial Activity, Ryerson University.

Netzell, O. (2013). The effect of accessibility on retail rents: testing integration value as a measure of geographic location. Journal of Property Research, 30(1), 1-23. DOI: 10.1080/09599916.2012.713974

Neuman, W. L., \& Robson, K. (2012). Basics of social research: Qualitative and quantitative approaches (2nd ed.). Toronto, ON: Pearson.

Pantazis, G. (2016, March 23). Queen street east restaurant study [Community Consultation Meeting]. City of Toronto.

Phan, M.B. \& Luk, C.M. (2005). Ethnic enclave reconfiguration: A new' Chinatown in the making. GeoJournal, 64, 17-30. DOI: 10.1007/s10708-005-3920-7

Ratcliffe, J. and Flanagan, S. (2004). Enhancing the vitality and viability of town and city centres. Property Management, 22(5), 337-395. DOI 10.1108/02637470410571210

Ravenscroft, N. (2000). The vitality and viability of town centres. Urban Studies 37, 2533-2549. 
Schabas, J. (2012). The condo retail we need. Spacing Toronto. Retrieved (March 3, 2016) from http://spacing.ca/toronto/2012/07/18/the-condo-retail-we-need/

Silverman, R.M., Taylor, H. L., and Crawford, C. (2008). The role of citizen participation and action research principles in Main Street revitalization. Action Research, 6(1), 69-93. DOI: $10.1177 / 1476750307083725$

Sohn, D. (2016). Residential crimes and neighbourhood built environment: assessing the effectiveness of crime prevention through environmental design (CPTED). Cities, 52, 86-93. DOI:10.1016/j.cities.2015.11.023

Solomon, L. (2007). Toronto Sprawls: A History (Toronto, ON): University of Toronto Press. Retrieved from Google Books.

Streetsense. (2012). DC vibrant retail streets toolkit. Prepared for DC Office of Planning. Retrieved (March 3, 2016) from http://hstreet.org/wp-content/uploads/2012/04/DCVibrant-Streets-Toolkitby-Streetsense1.pdf

Sutton, S. A. (2010). Rethinking commercial revitalization: A neighbourhood small business perspective. Economic Development Quarterly, 24(4), 352-371. DOI: 10.1177/0891242410370679

Uneke, O. (1996). Ethnicity and small business ownership: contrasts between Blacks and Chinese in Toronto. Work, Employment \& Society, 10(3), 529-548.

Urban Land Institute. (1987). Mixed-use development handbook. Washington, DC: Author.

Urban Metrics. (2010). City of Vaughan Commercial land use review: 3. Retail development trends. Prepared for City of Vaughan. Retrieved (March 3, 2016) from https://www.vaughan.ca/projects/policy_planning_projects/General\%20Documents/Background \%20Papers/Commercial\%20Land\%20Use\%20Review/22fVaughan\%20CLR\%20Final-retail.pdf

Witherspoon, R. E. et al. (1976). Mixed-use development: new easy of land use. Washington, DC: Urban Land Institute.

Wright, G. (Consolidated 2010). Toronto official plan. City of Toronto. (Toronto, ON).

Yeates, M. and Montgomery, D. (1999). The changing commercial structure of non-metropolitan urban centres and vacancy rates. The Canadian Geographer, 43(4), 382-399.

Yeates, M., Hernandez, T. and Murray, A. (2015). Commercial strips in the GTA. Toronto: Centre for the Study of Commercial Activity, Ryerson University. 


\section{DATA REFERENCES}

Centre for the Study of Commercial Activity. CSCA's data warehouse [tubular data]. Toronto, Ontario: Ryerson University, n.d. Retrieved (March 3, 2016) from http://www.csca.ryerson.ca/Databases.html

City of Toronto. (n.d.) b. Toronto's Interactive Map [interactive map]. Retrieved (March 3, 2016) from http://www1.toronto.ca/wps/portal/contentonly?vgnextoid=15dede0230460410VgnVCM1000007 1d60f89RCRD

City of Toronto Geospatial Competency Centre. City of Toronto property data maps [digital resource: vector]. Toronto, Ontario: City of Toronto, 2013 . Retrieved (March 3, 2016) from https://library.cf.ryerson.ca/madar/geospatial/libdata/action2b.cfm?ResourceID=56220

Darkwah, K. (2015) a. 2014 Leslieville BIA. City of Toronto [Infographic]. Retrieved (March 3, 2016) from http://www1.toronto.ca/wps/portal/contentonly?vgnextoid=a604ba5e81fc6410VgnVCM1000007 1d60f89RCRD\&vgnextchannel=ea3032d0b6d1e310VgnVCM10000071d60f89RCRD

Darkwah, K. (2015) b. 2014 Riverside District BIA. City of Toronto [Infographic]. Retrieved (March 3, 2016) from http://www1.toronto.ca

Darkwah, K. (2015) c. 2014 The Beach BIA. City of Toronto [Infographic]. Retrieved (March 3, 2016) from http://www1.toronto.ca

Environics Analytics. (n.d.). Simply Map Canada 3.0 [mapping and tubular data tool]. Retrieved through Ryerson University Library (March 3, 2016) from http://www.simplymap.com.ezproxy.lib.ryerson.ca/index.html

Friesen, D. and Rajagopalan, P. (n.d.). Toronto Crime by Neighbourhood [interactive map]. Retrieved (March 3, 2016) from http://www.cbc.ca/toronto/features/crimemap/

Walk Score. (n.d.). Retrieved (March 3, 2016) from https://www.walkscore.com/ 